\title{
ULUSLARARASI ENTEGRE RAPORLAMA ÇERÇEVESİNDE MUHASEBE KÜLTÜRÜ ${ }^{1}$
}

\section{ACCOUNTING CULTURE IN INTERNATIONAL INTEGRATED REPORTING FRAMEWORK}

\author{
Gözde KARABURUN ${ }^{a *}$ \\ a* Sorumlu Yazar, Bilim Uzmanı, İzmir Katip Çelebi Üniversitesi Sosyal Bilimler Enstitüsü Doktora Öğrencisi, \\ gozdekaraburun@gmail.com, ORCID: 0000-0002-9443-4146
}

\section{MAKALE BİLGÍLERİ}

\section{Makale Tarihçesi:}

Gönderilme Tarihi 16.05.2020

Düzenleme 16.06.2020

Kabul Tarihi 20.06.2020

Anahtar Kelimeler: Entegre Raporlama, Uluslararası Entegre Raporlama Çerçevesi, Muhasebe Kültürü, Muhasebe Kültürü Değerleri

Jel Kodlart: M14, M40, M41

\section{ARAŞTIRMA MAKALESI}

\section{BENZERLIK/ PLAGIARISM}

Ithenticate : $\% 8$

\section{ÖZET}

Son dönemlerde uygulama alanı bulan entegre raporlama, şirketlerin finansal bilgilerinin yanı sıra finansal olmayan bilgileri de raporlamasını sağlayan bir raporlama şeklidir. Entegre raporlar Uluslararası Entegre Raporlama Çerçevesine uygun bir şekilde hazırlanmaktadır. Bu çalışmada Uluslararası Entegre Raporlama Çerçevesi, S. J. Gray tarafindan 1988 yllında kaleme alınan "Towards a Theory of Cultural Influence on the Development of Accounting Systems Internationally" başlıklı çalışmada tanımlanan muhasebe kültür değerleri açısından analiz edilmiştir. Bu çalışmanın amacı, Uluslararası Entegre Raporlama Çerçevesinin muhasebe kültürü değerlerine ĕgilimi üzerine önermelerde bulunmak ve bu önermeleri desteklemektir. Uluslararasi Entegre Raporlama Çerçevesi Gray'in muhasebe kültürü değerlerine göre incelendiğinde profesyonellikten, esneklikten, tutuculuktan ve şeffaflıktan yana bir eğilim içinde olduğ yorumu yapilabilmektedir.

\footnotetext{
${ }^{1}$ Bu çalışma İzmir Katip Çelebi Üniversitesi Sosyal Bilimler Enstitüsünde hazırlanan Enstitüsünde "Muhasebe Kültürü ve Entegre Raporlama Farkındalı̆̆ İlişkisi” isimli tez çalışmasından türetilmiştir.
}

APA STILI KAYNAK KULLANIMI: KARABURUN, G . (2020). ULUSLARARASI ENTEGRE RAPORLAMA ÇERÇEVESINDE MUHASEBE KÜLTÜRÜ . Muhasebe ve Finans Incelemeleri Dergisi, 3(2), 85 - 103 . DOI: 


\section{ARTICLE INFO}

Article history:

Received 16.05.2020

Revised 16.06.2020

Accepted 20.06.2020

Keywords: Integrated Reporting, International Integrated Reporting Framework, Accounting Culture, Accounting Culture Values

Jel Codes: M14, M40, M41

\begin{abstract}
Integrated reporting, which has recently found field of application, is a form of reporting that allows companies to report non-financial information as well as financial information. Integrated reports are prepared in accordance with the International Integrated Reporting Framework. In this study, the International Integrated Reporting Framework was analyzed in terms of accounting culture values defined by the study titled "Towards a Theory of Cultural Influence on the Development of Accounting Systems Internationally" written in 1988 by S. J. Gray. The aim of this study is to make suggestions on the tendency of the International Integrated Reporting Framework to the accounting culture values and to support these propositions. When the International Integrated Reporting Framework is analyzed according to Gray's accounting culture values, it can be interpreted that it has a tendency towards professionalism, flexibility, conservatism and transparency.
\end{abstract}

\section{GíRiş}

Entegre raporlama, yatırımcıları bütün olarak bilgilendirmekte ve işletmenin gelecek performans1 üzerine doğru kararlar alabilmelerini sağlamaktadır. Bir kurumun hem geriye dönük bilgileri hem de ileriye dönük vizyonu entegre rapor ile paylaşılabilmektedir. 2013 yılında Uluslararası Entegre Raporlama Konseyi, Uluslararas1 Entegre Raporlama Çerçevesini yayımlamıştır. İlkelere dayalı olan bu çerçeve, giriş bölümü ve entegre rapor bölümü olmak üzere iki bölümden oluşmaktadır. Çerçevenin kullanımı ve entegre rapordaki temel kavramları giriş bölümü açıklarken, kılavuz ilkeleri ve içerik öğelerini entegre rapor bölümü açıklamaktadır.

Hofstede 1980 yılında kültürel farklılıkları dört boyutta ele almıştır. Güç mesafesi, Belirsizlikten kaçınma, Bireyselci-Kolektivist yap1 ve MaskülenFeminen toplumdan oluşan bu dört boyut S. J. Gray'in çalışmasının temelini oluşturmaktadır. 1988 yılında Gray, Hofstede'in kültürel boyutlarını esas alarak muhasebe kültürü değerleri adını verdiği profesyonelliğe karşı statükoculuk, tekdüzeliğe karşı esneklik, tutuculuğa karşı iyimserlik ve gizliliğe karşı şeffaflık boyutlarını tanımlamıştır.

$\mathrm{Bu}$ çalışmada, Uluslararası Entegre Raporlama Çerçevesinin muhasebe kültürü değerlerine eğilimi üzerine önermelerde bulunulmuştur. İleri sürülen bu önermeleri güçlendirmek Uluslararası Entegre Raporlama Çerçevesinin Gray'in muhasebe değerleriyle benzer yanlarına yer verilmiştir.

\section{LITERATÜR ÇALIŞMASI}

birçok çalışmaya konu olmuştur. $\begin{gathered}\text { Uluslararası } \\ \text { Eürkiye'de }\end{gathered}$
Uluslararası Entegre Raporlama Çerçevesini kullanarak yapılan bazı çalışmalara kronolojik sırayla aşağıda yer verilmiştir.

Yüksel ve Aracı (2017) çalışmalarında, hizmet işletmelerine ait raporların çoğunluğunun Uluslararası Entegre Raporlama Çerçevesi içerik öğelerine uygun olarak hazırlandığını belirtmişlerdir. Ercan ve Kestane (2017) çalışmalarında, 2016 yılında Türkiye'de yayınlanan entegre raporların içerik analizini Uluslararası Entegre Raporlama Çerçevesine göre yapmıștır. Yüksel (2018) çalıșmasında, araştırma kapsamındaki işletmelerin 2014, 2015 ve 2016 yıllarına ait yıllık raporlarının içerik analizini Uluslararası Entegre Raporlama Çerçevesi içerik öğelerinden oluşturulan 38 adet ölçüt doğrultusunda yapmıștır. Dereköy (2018) çalıșmasında, çimento sektöründeki işletmelerden entegre rapor yayınlayanların entegre raporlarını içerik analizi yöntemi kullanarak Uluslararası Entegre Raporlama Çerçevesi bağlamında analiz etmiştir. Işgüden Kılıç (2018) çalışmasında, BIST sürdürülebilirlik endeksine kayitlı işletmelerin y1llık faaliyet raporları ile 2016 y1lına ait entegre raporlarını Uluslararası Entegre Raporlama Çerçevesi açısından incelemiştir. Ağdeniz (2018) çalışmasında, Uluslararası İç Denetim Standartları ile Entegre Raporlama çerçevesi ilkeleri arasında yakın bir ilişki olduğunu belirtmiştir. Yüksel (2018) çalışmasında, kurumsal yönetim ilkeleri ile Uluslararasi Entegre Raporlama Çerçevesi ilkeleri arasındaki ilişkiyi regresyon analizi ile incelemeye çalışmıştır. Ataman Gökçen ve Eldemir (2019) çalışmalarında, Türkiye'de yayınlanan entegre raporların, Uluslararas1 Entegre Raporlama Çerçevesine uygunluğunun tespit edilmesini amaçlamıştır.

Gray'in muhasebe kültürü değerleri makale yayınlandığı günden itibaren birçok çalışmaya konu olmuştur. Türkiye'de Gray'in muhasebe kültürü değerleri kullanılarak yapılan bazı çalışmalar kronolojik sırayla aşağıda yer almaktadır. 
Karabınar ve Güvenç (2006) tarafindan gerçekleştirilen çalışmaya göre İçel Serbest Muhasebeci ve Mali Müşavirler Odasına kayıtlı 198 kişiye anket uygulanması yapmıştır. Ana kütlenin \%41,94'üne ulaşmışlardır. Çalışma sonucunda muhasebe meslek mensuplarının profesyonellik, tekdüzelik, tutuculuk ve gizlilik eğilimde olduklarını belirtmiştir. Bekçi ve Bitlisli (2012) tarafından gerçekleştirilen çalışmada Isparta Serbest Muhasebeci ve Mali Müşavirler Odasına kayıtlı 121 muhasebe meslek mensubuna anket uygulanmıştır. Bu meslek mensupları ana kütlenin \%38'ini temsil etmiştir. Çalışmaları sonucunda muhasebe meslek mensuplarının profesyonellik, tekdüzelik, iyimserlik ve şeffaflık eğilimde olduklarını belirtmişlerdir. Durmuş ve Güneş (2017) tarafından gerçekleştirilen çalışmada, yeminli mali müşavirler odalarına bağlı 420 yeminli mali müşavire anket uygulanmıştır. Çalışma sonucunda muhasebe meslek mensuplarının profesyonellik, tekdüzelik, tutuculuk ve şeffaflık eğilimde olduklarını belirtmişlerdir.

Entegre raporlama ve kültürü ayrı ayrı ele alan çalışmalar olduğu gibi birlikte ele alan çalışmalar da bulunmaktadır. Entegre raporlama ve kültürü birlikte ele alan çalışmalara kronolojik sırayla aşağıda yer verilmiştir.

Meyrick (2016), günümüz toplumlarında kültürün somut niteliklerinin ve kültürel süreçlerin göz ard1 edildiğini veya az vurgulandığını belirtmektedir. Buna karşıllk kültürel etkinliklere ve organizasyonlara ilişkin politik kararların, onlar hakkında derinlemesine bilgi alınmadan verildiğini vurgulamaktadır. Entegre Raporlama, kuruluşların zaman içinde farklı sermaye alanlarında nasıl değer yarattığını göstermek için çabalamaktadır. Bu çalışma ile bilginin bağlanabilirliği olarak da adlandırılan bu duruma katkida bulunulmakta ve nicel verilerin anlamlı yorumlanmasinda anlatının rolüne odaklanılmaktadır. Çalışmada entegre raporlamanın kültürel raporlamayı kolaylaştırma kapasitesine sahip olduğu belirtilmektedir. Vitolla v.d. (2019), tarafindan gerçekleştirilen çalışmada, entegre raporlamanın sosyal ve çevresel boyutlar da dahil olmak üzere finansal olmayan boyutlara odaklanan diğer bilgilendirme sistemlerinin aksine bilgi bağlantısı ile nitelendirildiği belirtilmektedir. Son y1llarda, entegre raporlama hem akademik hem de profesyonel olarak ilgi görmesine rağmen, entegre rapor kalitesi ve belirleyicileri üzerine odaklanan az sayıda çalışma bulunmaktadır. Ulusal kültür ise dış belirleyici ve kurumsal raporların kalitesini etkileyen ek bir faktör olarak ele alınmaktadır. Bu çalışmada ulusal kültürün paydaş teorisi açısından etkisi araştırılmış ve bu boşluğu doldurmak amaçlanmıştır. Çalışmanın bir diğer özelliği, entegre raporlama kalitesinin belirleyicisi olarak ulusal kültürü araştıran ilk çalışmalardan olmasıdır. Çalışmada kurumsal raporların kalitesini etkileyen ulusal kültür faktörü analiz edilerek entegre raporlama kalitesinin Hofstede'nin beş boyutu ile ilişkili olduğunu gösterilmektedir. $\mathrm{Bu}$ çalışmaya göre entegre raporlama kalitesinin güç mesafesi, bireysellik, maskülenlik ve hoşgörü ile negatif ve belirsizlikten kaçınma ile pozitif ilişkisi vardır. Raimo vd. (2019), entegre raporlamanın kritik yönü olan raporların kalitesine odaklanan çalışmaların az olduğuna değinmektedir. Çalışma, entegre raporlama kalitesini etkileyen ek bir faktör olarak ulusal kültürün entegre raporlama kalitesi üzerindeki etkisini analiz ederek ilgili literatüre katkıda bulunmaktadır. Çalışma sonucunda entegre raporlama kalitesinin altı GLOBE boyutuyla ilişkili olduğu gösterilmektedir. Girişkenlik, kurumsal toplulukçuluk, belirsizlikten kaçınma ve insan odaklılık ile pozitif, performans odaklılık ve gelecek odaklılık ile negatif ilişkisi vardır. Aynı zamanda sonuçlar, firmaların faaliyet gösterdiği ülkelerin ulusal kültürünün entegre raporlama kalitesini etkilediğini göstermektedir. Çalışmada bu araştırmanın sonuçlarının hükümetler, yöneticiler ve Uluslararası Entegre Raporlama Konseyi açısından önem arz ettiği belirtilmiştir. Politika yapıcıların açıklamaları düzenlerken ulusal kültürü hesaba katmaları gerektiğgi vurgulanmıștır. Uluslararasılaşma durumunda, yöneticilerin yeni ülkelerin kültürünü hesaba katmaları ve yeni pazarlarda kabul görmek için açıklama stratejilerini değiştirmeleri gerektiği belirtilmektedir. Son olarak Uluslararas1 Entegre Raporlama Konseyi'nin Uluslararası Entegre Raporlama Çerçevesini geliștirirken, faaliyet gösterilen ülkelerin kültürüne özgü araçlar sunmak amacıyla farklı ülkelerin kültürel özelliklerini dikkate alması gerektiği savunulmuştur.

\section{ULUSLARARASI RAPORLAMA ÇERÇEVESİ \\ ENTEGRE}

$\mathrm{Bu}$ Entegre raporlama hem finansal hem de finansal olmayan verilerin birlikte sunuldukları ve karmaşık olmayan bir kurumsal rapor türüdür. Entegre raporlamayla ilgili dünya çapında araştırmaların hız kazanması 2010 yılında Uluslararas1 Entegre Raporlama Konseyi'nin (International Integrated Reporting Council-IIRC) kurulması ile başlamıştır. IIRC kuruluşundan itibaren işletmelere entegre rapor hazırlarken yön gösterecek, uluslararası mecrada kabul görmüş olan bir entegre raporlama çerçevesinin hazırlanmasını misyonu olarak belirlemiștir. Uluslararası Entegre Raporlama Çerçevesi IIRC tarafindan 5 Aralık 2013 yılında yayımlamıştır (Aras ve Uğur Sarığlu, 2015: 42). 2013 yılının sonlarına doğru yayınlanan Entegre Raporlama Çerçevesinin 2014 y1lı içinde Türkçe sürümü de yayınlanmıștır (Borsa İstanbul, 2014: 35).

Uluslararası Entegre Raporlama Çerçevesi ilke bazlıdır. Çerçevenin ilkelere dayalı olmasının 
sebebi esneklik ve düzen içinde, kendine ait koşulları bulunan farklı kuruluşlar arasında karşılaştırılabilir bir seviye oluşturmaktır. İlkeler farklı kuruluşların arasındaki büyük farklılıkları da dikkate alır ve bilgi ihtiyacını karşılamak için bir denge sağlar (IIRC, 2013: 7).

Entegre raporun içeriğini düzenleyen ve oluşturan kılavuz ilkelerin, içerik öğelerinin ve dolayısıyla temel kavramların açıklanması bu çerçevenin amacını oluşturmaktadır (IIRC, 2013: 7).

\subsection{Temel Kavramlar}

Temel kavramlar Uluslararası Entegre Raporlama Çerçevesindeki ihtiyaçların ve kılavuz bilgilerin esasını oluşturmakta ve bu bilgileri desteklemektedir. Bir entegre rapor, kuruluşu etkileyen dış çevre ve sermaye öğeleri hakkında bilgi verme amacındadır. Kuruluşun diş çevresi ve sermaye öğeleriyle değer yaratmak amaciyla etkileşim kurması entegre raporun bir diğer amacıdır (IIRC, 2013: 10).

\section{Yaratma}

\subsubsection{Kuruluş ve Diğerleri için Değer}

Bir kuruluş zaman içinde değer yaratır ve yaratılan bu değer, sermaye öğeleri üzerine kendini gösterir. Sermaye öğeleri üzerindeki artışlar, azalmalar veya dönüşümler, kuruluşun faaliyetleri ve çıktıları aracılığıyla meydana gelmektedir. Kuruluşun kendisi için yaratılan değer ve diğerleri için yaratılan değer olmak üzere birbiriyle ilişkili iki öğesi vardır. Kuruluşun kendisi için yarattığ 1 değerle ilgilenenler finansal sermaye sağlayanlardır. Finansal sermaye sağlayanlar, kuruluş tarafından diğer taraflar için yaratılan ve kuruluşun kendisini de etkileyen değerlerle de ilgilenirler (IIRC, 2013: 10).

\subsubsection{Sermaye Öğeleri}

Kuruluşlar başarıya ulaşmak için çeşitli sermaye öğelerine ihtiyaç duyar. Sermaye öğeleri bir değerler stokudur. Kuruluşun faaliyetleri ve sonuçlarıyla artar, azalır ya da dönüştürülür. Sermaye öğelerinin genel stoku sabitlenmez. Sermaye öğeleri kendi içlerinde ve aralarında bir akış içindedir. Uluslararası Entegre Raporlama Çerçevesinde sermaye öğeleri; finansal, üretilmiş, fikri, insan kaynakları, sosyal, ilişkisel ve doğal sermaye öğeleri olarak sınıflandırılmıştır (IIRC, 2013, 11).

Finansal Sermaye: Finansman, faaliyetler veya yatırımlar yoluyla edinilme ve hizmet sağlama veya mal üretimi amaciyla bir kuruluşun kullanımına sunulma gibi özelliklere sahip olan fon havuzudur (IIRC, 2013: 11).

Üretilmiş Sermaye: Bir kuruluşun mal üretmek ya da hizmet sağlamak için kullanıma sunduğu üretilmiş fiziksel nesneler üretilmiş sermaye olarak adlandırılır. Çerçevede binalar, ekipmanlar, karayolları, köprüler, limanlar, atık ve su arıtma tesisleri gibi altyapılar üretilmiş sermaye olarak açıklanmıştır (IIRC, 2013: 12).

Fikri (Entelektüel) Sermaye: Patentler, telif hakları gibi kuruluşa ait bilgiye dayalı maddi olmayan varlıkları ifade eden sermaye öğesidir (IIRC, 2013: 12).

- İnsan Sermayesi: İnsana ait olan yeterlilikler, deneyimler, kabiliyetler ve yenilik yapma motivasyonları insan sermayesini oluşturur. Insanların kuruluşa ait kurumsal yönetim çerçevesini, etik değerlerini ve risk yönetimi yaklaşımını desteklemeleri ve bunlara uyum sağlamaları insan sermayesinin özelliklerindendir (IIRC, 2013: 12).

Sosyal ve İlişkisel Sermaye: Paydaş grupları, toplumlar ve diğer ağların hem kendi içindeki ve hem de aralarındaki gelenek ve ilişkilerle, bireysel refah ve toplu refahı çoğaltmak için bilgi paylaşma kabiliyeti sosyal ve ilişkisel sermaye olarak tanımlanır (IIRC, 2013: 12).

Doğal Sermaye: Su, toprak, madenler, biyolojik çeşitlilik ve ekosistem sağlığı gibi bir kuruluşun refahını destekleyen yenilenebilir ve yenilenemez doğal kaynaklar ve süreçlerdir (IIRC, 2013: 12).

\subsubsection{Değer Yaratma Süreci}

Dış çevre bileşeni, toplumsal sorunları, çevresel zorlukları, ekonomik koşulları ve teknolojik değişimleri içerir. Aynı zamanda kuruluşun etkinlik gösterdiği bağlamı oluşturur. Misyon ve vizyon bileşenleri, kuruluşun tamamını kapsar. Kuruluşun hangi amaca hizmet ettiğini ve niyetinin ne olduğunu anlaşılır, öz ve kısa terimlerle açıklar. Kurumsal yönetim sorumluları, kuruluşun değer yaratma yeteneğini destekleyen yönetim yapısı meydana getirmekten sorumludur. Kuruluşun temelini iş modeli oluşturur. İş modeli, girdi olarak sermaye öğelerini kullanır ve iş etkinlikleri yoluyla bunları hizmet, ürün, yan ürün ve atık olarak çıtıya dönüştürür. Kuruluşun etkinlikleri ve çıktıları, sermaye öğeleri üstündeki etki bakımından sonuçları doğurur. İş modelinin değişime uyarlanma kapasitesi, kuruluşun uzun sürede yaşayabilirliğini etkileyebilmektedir (IIRC, 2013: 13).

\subsection{Entegre Rapor Kilavuz Ilkeleri}

Bir entegre rapor hazırlanırken ve sunulurken k1lavuz ilkeler temel alınır. $\mathrm{Bu}$ ilkeler, raporun içeriğiyle ilgili bilgi verir ve bilgilerin hangi yolla sunulduğunu gösterir (IIRC, 2013: 16). Kilavuz ilkelerini;

- $\quad$ Stratejik odak ve geleceğe yönelim

- $\quad$ Bilgiler arası bağlantı

- $\quad$ Paydaşlarla ilişkiler

- $\quad$ Önemlilik

- $\quad$ Kisa ve öz olma

- $\quad$ Güvenilirlik ve eksiksizlik

- Tutarlılık ve karşılaştırabilirlik şeklinde sıralayabiliriz.

Bir entegre rapor hazırlanırken ve sunulurken k1lavuz ilkeler ayrı ayrı kullanılabileceği gibi birlikte de kullanılabilir. Kısa ve öz olma ile eksiksiz olma arasında olduğu gibi aralarında belirgin bir çatışma olan ilkele söz konusu olabilir. $\mathrm{Bu}$ bilgiler 
uygulanırken çok iyi muhakeme edilmelidir (IIRC, 2013: 16).

\subsubsection{Stratejik Odak ve Geleceğe Yönelim}

Bir entegre rapor kuruluşun stratejisi üzerine bilgi vermelidir. Kuruluşun kısa, orta ve uzun vadeli değer yaratma kabiliyeti ile ilgili bilgileri de içeren entegre rapor, sermaye öğelerinin kullanımı ve etkileşimi üzerine bilgi sağlamalıdır (IIRC, 2013: 16).

\subsubsection{Bilgiler Arası Bağlantı}

Entegre rapor kuruluşun belirli bir zaman zarfinda değer yaratma yeteneğini etkileyen etkenlerin birleşimini, birbirleriyle ilişkilerini ve aralarındaki bağımlılıkların bütün olarak bir resmini sunmalidir (IIRC, 2013: 16).

\subsubsection{Paydaşlarla İliş̧kiler}

Bir entegre rapor, kuruluşun temel paydaşlarıyla kurduğu ilişkilerle ilgili olarak bilgi vermelidir. Entegre rapor, kuruluşun paydaşların yasal ihtiyaç ve isteklerinin anlaşılma, hesaba katılma ve karşılanma ölçüsünü göstermelidir (IIRC, 2013: 17).

\subsection{4. Önemlilik}

Bir entegre rapor, kuruluşun değer yaratma yeteneğini kısa, orta ve uzun vadede ve önemli ölçüde etkileyen konular hakkında bilgiler içermelidir (IIRC, 2013: 18).

\subsubsection{Kisa ve Öz Olma}

Entegre rapor kısa ve öz olmalıdır (IIRC, 2013: 21). Entegre raporların k1sa ve öz olmasının nedeni okunabilirliğinin artırılmak istenmesidir. Bir entegre raporun kısa ve öz olmasına katkıda bulunan ilke önemlilik ilkesidir. Entegre raporun gereksiz yere uzamasını engellemek için tekrarlardan kaçınılmaktadır (Saban vd., 2017: 927).

\subsubsection{Güvenilirlik ve Eksiksizlik}

Bir entegre rapor olumlu veya olumsuz bütün maddi konuları dengeli içermelidir. Maddi hataya yer vermeyecek şekilde düzenlenmelidir (IIRC, 2013, 21).

\subsubsection{Tutarlılık ve Karşılaștırabilirlik}

Entegre rapordaki bilgiler, zaman içinde tutarlı bir temele dayalı olarak sunulmalıdır. $\mathrm{Bu}$ bilgiler, kuruluşun değer yaratma kabiliyeti açısından, diğer kuruluşlarla karşılaştırılacak şekilde sunulmalıdır (IIRC, 2013: 23).

\subsection{Entegre Rapor Içerik Öğeleri}

Bir entegre rapor aşağıdaki sekiz içerik öğesini ve bunlarla ilgili soruların cevaplarını içermelidir (IIRC, 2013: 24). Bunlar;

- Kurumsal genel görünüm ve diş

çevre

- $\quad$ Kurumsal yönetim

- $\quad$ İș modeli

- $\quad$ Riskler ve firsatlar

- $\quad$ Strateji ve kaynak aktarımı

- $\quad$ Performans

- $\quad$ Genel görünüş

- Hazırlık ve sunum temeli
Çevre

- Genel raporlama ilkeleri

3.3.1. Kurumsal Genel Görünüm ve Dış

Entegre rapor, kurumun misyon ve vizyonunu iletmesi için bir platform sağlar (Serafeim, 2016: 18). Kuruluşun kısa, orta ve uzun vadede değer yaratma yeteneğini etkileyen yasal, ticari, çevresel, toplumsal ve siyasal faktörler başta olmak üzere bütün diş faktörler entegre raporda yer almalıdır. $\mathrm{Bu}$ dış faktörlere ekonomik dengeye etki eden mikro ve makroekonomik koşulları, müșteri talebindeki değişimleri, teknolojik gelişmeleri, iklim değişikliğini veya yasal değişiklikleri de eklenebilir (Aras ve Uğur Sarığlu, 2015: 60).

\subsubsection{Kurumsal Yönetim}

Entegre rapor; beceri ve çeşitlilik yelpazesi, ücret ve teşviklerin uyumlaştırılması, organizasyon kültürünün yönetilmesi, izlenmesi ve riske karş1 tutum gibi bilgileri içererek bir kuruluşun yönetim yapısı hakkında bilgi sağlayabilir (Serafeim, 2016: 19). Kurumsal yönetim öğesi kapsamında entegre raporda yer alan bilgiler, paydaşların değerlendirmede bulunabilmelerine olanak sağlamalıdır (Aras ve Uğur Sarığlu, 2015: 61).

\subsection{3. İs Modeli}

İş modeli, bir kurumun girdilerini çıktılara ve sonuçlara dönüștürmek için iș faaliyetlerini nasıl kullandığını açıklar. Aynı zamanda iş modeli, örgütün stratejik amaçlarını yerine getirmeyi ve kısa, orta ve uzun vadede değer yaratmayı amaçlamaktadır (Serafeim, 2016: 20). Olumlu sonuçlara sermaye öğelerinde net artışla sonuçlanan yani değer yaratanlar örnek gösterilirken olumsuz sonuçlara sermaye öğelerinde net azalmayla sonuçlanan yani değeri azaltanlar örnek gösterilebilir (IIRC, 2013: 26).

\subsubsection{Riskler ve Fursatlar}

Yatırımcılar işletmenin gelecekteki performansına dolayısıyla da işletmenin firsatlarına ve risklerine odaklanmış durumundadırlar. Sahip olunan firsatlar ve karșı karşıya kalınan riskler yatırımcıların dikkat ettiği alanlardan sayılabilir. İşletmeler SWOT analizi yaparak risklerini ve firsatlarını belirleyebilir (Saban vd., 2017: 931). Riskleri ve firsatları tanımlamak, ortaya çıktıklarında onları tanımakla sınırlı değildir. Aynı zamanda gerçekleşme ihtimalini de değerlendirmek demektir. Riskleri azaltmayı veya yönetmeyi ve firsatlardan yararlanmayı hedefleyen eylemler, entegre raporda mevcut olmalidır (Serafeim, 2016: 21).

\subsubsection{Strateji ve Kaynak Aktarımı}

İşletmenin stratejik hedeflerini ve geleceğe yönelik beklentilerini stratejik odak ve geleceğe yönelim kılavuz ilkesi gereğince bilgi kullanıcılarına aktarması gerekmektedir. Kuruluşun stratejik hedeflerinin değerlendirildiği strateji ve kaynak aktarımı bölümünde, rekabet avantajı sağlayacak faktörlerin sayisal verilerle desteklenmesi ve sunulmas1 önerilmektedir (Saban vd., 2017: 932). 
Strateji ve kaynak aktarımı, bu hedeflere yönelik kaynak tahsis planları ile birlikte kısa, orta ve uzun vadeli tüm stratejik hedefleri içerir (Serafeim, 2016: 22).

\subsubsection{Performans}

Performans öğesi, işletmenin stratejik hedeflerine ulaşma ölçüsünü içermektedir. Hem nicel hem de nitel veriler kullanilarak hazırlanan entegre rapor sayesinde yatırımcılar işletmenin performansını daha rahat değerlendirebilirler. Entegre raporda gelir artışı gibi finansal performansa dair verilerin bulunmasının yanı sıra müşteri ilişkilerini güçlendirme çalışmaları ve sonuçları gibi finansal olmayan verilere de yer verilmelidir (Saban vd., 2017: 932). Daha ayrıntılı performans verileri için finansal veya sürdürülebilirlik raporları gibi diğer kurumsal raporlar kaynak gösterilebilir (Aras ve Uğur Sarığlu, 2015: 64).

\subsubsection{Genel Görü̈nüs}

Entegre rapor çok sayıda bilgiyi ve bu bilgilerin dayandığı öngörüleri içerir. Yapılan tüm değerlendirmelerin toplu bir şekilde sunulması genel görüş öğesince önerilmektedir (Saban vd., 2017: 932). Entegre rapor, bir şirketin diş etkenlerini ve karşılaşabileceği zorlukları ve firsatları tartışması için olanak verebilir (Serafeim, 2016: 23).

\subsubsection{Hazırlık ve Sunum Temeli}

Entegre rapor çeşitli ilkeler ve öğeler çerçevesinde hazırlanmaktadır. Bu da her raporu, kendine özgü sinırlılıkları olan bir rapor bir hale getirmektedir. Yatırımcılar değerlendirmelerini yaparken bu sinırlılıkları ve açılamalarını göz önünde bulundurmalıdırlar (Saban vd., 2017: 933).

Genel raporlama ilkeleri, maddi konuların ve sermaye öğelerinin açıklamalarını, kısa, orta ve uzun vadeye ilişkin ek açıklamaları ve dikkat edilmesi gereken konuları içerir (Aras ve Uğur Sarığlu, 2015: $65)$.

\section{MUHASEBE KÜLTÜRÜ}

Kültür, insan davranışının ve toplumsal değerlerin altında yatan güçlü bir etkendir. $\mathrm{Bu}$ nedenle muhasebe uygulamaları üzerindeki etkisi ihmal edilemez (Koleśnik, 2013: 33). Muhasebe değerleri muhasebe sistemlerini etkiler. $\mathrm{Bu}$ nedenle kültürel faktörler, ulusal düzeyde kalkınma ve finansal sistemler üzerinde bir etkiye sahiptir (Koleśnik, 2013: 35). Muhasebe-kültür ilişkisi Gray tarafından belirlenen muhasebe değerleriyle ifade edilmiştir (Karabınar, 2005: 32).

S. J. Gray 1988 y1lında Abacus dergisinde yayınladığı "Towards a Theory of Cultural Influence on the Development of Accounting Systems Internationally (Uluslararası Muhasebe Sistemlerinin
Geliştirilmesi Üzerine Bir Kültürel Etkiye Doğru)" adlı makalesinde Hofstede'in güç mesafesi, bireyselcikolektivist yap1, maskülen-feminen toplum ve belirsizlikten kaçınma kültürel boyutlarını esas alarak muhasebe değerleri adını verdiği dört boyutu tanımlamıştır. Bunlar; profesyonelliğe karş1 statükoculuk, tekdüzeliğe karşı esneklik, tutuculuğa karşı iyimserlik ve gizliliğe karşı şeffaflık değerleridir.

\subsection{Profesyonellik-Statükoculuk}

Profesyonelliğe karşı statükoculuk (yasalarla kontrol), sık1 kurallara yaslanan yasal gereklilik ve kontrollere karşı bireye özgü olan profesyonel yargıları ve kişiye ilişkin sürdürülebilir profesyonel düzenlemeleri içeren bir tercihtir (Durmuş ve Güneş, 2017: 86). Profesyonel tutumlar benimseyen muhasebeciler tarafindan bireysel kararlara olan inanç, bağımsızlık ve bireysel çabaya saygı daha fazla vurgulanmaktadır. Tarafsız olmak, az sayıda kurala tabi olmak profesyonellik değeri ile tutarlıdır (Gray, 1988: 9). Profesyonelliğe karş1 statükoculuğun önemli bir muhasebe değeri olarak önerilmesinin nedeni, dünyanın farklı yerlerindeki muhasebe uygulayıcılarının uygulamaları sırasında mesleki yargılarında bağımsız davranabilme isteğidir (Durmuş ve Güneş, 2017: 86).

\subsection{Tekdüzelik- Esneklik}

Tekdüzeliğe karşı esneklik muhasebe değeri farklı yorumlara açık bir değerdir. Esneklik, şirketler arasında karşılaştırılabilirlik açısından kaygıya sebep olmaktadır. Buna ek olarak, zamanla şirket içinde meydana gelebilecek farkl1lıklar da tutarlılık açısından kaygıya sebep olmaktadır. $\mathrm{Bu}$ değer bireysel şirketlerin koşullarına uygun muhasebe uygulamalarının göreceli esnekliğine açıktır (Gray, 1988: 9).

\subsection{Tutuculuk- Iyimserlik}

Tutuculuk, gelecekteki olayların belirsizliği ile baş edebilmek için ihtiyatlı bir yaklaşımı ifade etmektedir. Iyimserlikte ise laissez-faire (Bırakınız yapsınlar) ideolojisine göre hareket edilir. İyimserliği benimseyenler daha optimistiktir ve risk almaya meyillidir (Gray, 1988: 8). Muhasebe alt kültüründe tercih edilen tutarlılık derecesi kullanılan ölçüm uygulamalarını etkileyecektir. Tutarlılığın derecesi ne kadar yüksek olursa geleneksel ölçme uygulamalarıyla olan bağlar o kadar güçlü olmaktadır (Choi, 2002: 77).

\subsection{Gizlilik-Şeffaflık}

Şeffaflık, kamuya açık bir yaklaşım ve daha anlaşılır olmak anlamına gelmektedir. Gizlilik ise iş ve işletme hakkındaki bilgilerin açıklanması sırasında kısıtlı bilgi paylaşılmasını ifade etmektedir (Gray, 1988: 8). Bir başka ifadeyle gizlilik değeri, işletmelerin finansal ve yönetim durumu ile ilgili gizliliği ve paylaşılan bilgilerin kısıtlanmasına yönelik bir yaklaşımdır. Şeffaflık değeri, paylaşılan bilgilerin daha açık olmasını ve kamuya hesap 
verilebilir bir yaklaşımdır. Gizliliğe karşı şeffaflık ise bu iki değer arasındaki tercihtir. İşletmelere ait bilgiler ilan edilirken gizlilik ve yasaklama mali tablolarda bulunan ulaşılabilir bilgi düzeyini azaltır ve değerlendirmelerde sorun yaratır. $\mathrm{Bu}$ durum sonucunda kişiler, mali tablolarda bulunan içerik düzeyi ile muhasebe uygulamalarındaki gizlilik düzeyi arasında olumlu olmayan bir ilişki olduğu tahminine yönelir (Durmuş ve Güneş, 2017: 86).

\subsection{Türkiye'deki Muhasebe Kültürü̈}

Türkiye'de Gray'in muhasebe değerlerini kullanarak yapılan bazı çalışmalara kronolojik sırayla aşağıda yer verilmiştir. Sırasıyla Türkiye'de statükoculuğa karş1 profesyonellik, tekdüzeliğe karş1 esneklik, tutuculuğa karşı iyimserlik ve gizliliğe karş1 şeffaflık değerleri ele alınmıştır.

İlk olarak çalışmalar, statükoculuğa karş1 profesyonellik değerine göre incelenmiştir. Karabınar ve Güvenç (2006), çalışmalarında ortalama değer 1,761 çıkmıştır. Bu çalışma profesyonel yaklaşımın büyük bir çoğunluk tarafından benimsendiğini göstermiştir. Bekçi ve Bitlisli (2012), çalışmaları sonucunda statükoculuğa karş1 profesyonellik değerini 2,1984 olarak bulmuştur. Bu durum ankete katılan muhasebe meslek mensuplarının profesyonellikten yana olduklarını göstermektedir. Durmuş ve Güneş (2017), çalışmalarında, 2,2023 ortalama değeri ile meslek mensuplarının büyük ölçüde profesyonellikten yana olduklarını belirlemişlerdir.

İkinci olarak tekdüzeliğe karşı esneklik değerine göre çalışmalar incelenmiştir. Karabınar ve Güvenç (2006), çalışmalarında aritmetik ortalamayı 3,039 bulmuş ve ankete katılanların tekdüzelikten yana olduklarını belirtmiştir. Bekçi ve Bitlisli (2012), çalışmalarında anket ortalamasını 3,3781 bulmuştur. Çalışmaya katılan muhasebe meslek mensuplarının tekdüzelik eğiliminde olduklarını vurgulamışlardır. Durmuş ve Güneş (2017), çalışmalarında, ortalama değeri 2,7238 olarak tespit etmiştir. $\mathrm{Bu}$ sonucu değerlendirdiklerinde meslek mensuplarının tekdüzelik eğiliminde olduklarını görmüşlerdir.

Üçüncü olarak çalışmalar tutuculuğa karşı iyimserlik değerine göre incelenmiştir. Karabınar ve Güvenç (2006), çalışmalarında ortalama değeri 3,36 bulmuştur. $\mathrm{Bu}$ sonucu kararsızlığa yakın olmakla birlikte tutuculuk yönünde eğilim olduğu şeklinde yorumlamışlardır. Bekçi ve Bitlisli (2012), çalışmalarında ankete katılan meslek mensuplarına ait cevapların ortalamasını 3,7293 olarak bulmuştur. $\mathrm{Bu}$ değer kararsızlığa yakın olmakla birlikte, meslek mensupları az farkla olsa da iyimserlik eğilimindedirler. Durmuş ve Güneş (2017), çalışmalarında, ortalama değeri 2,9964 olarak tespit etmiştir. Meslek mensuplarının tutuculuk değerine daha yakın olduklarını belirtmiştir.

Son olarak gizliliğe karşı şeffaflık değerine göre çalışmalar incelenmiştir. Karabınar ve Güvenç
(2006), çalışmalarında bu değere yönelik aritmetik ortalamay1 3,58 olarak tespit etmişlerdir. Ankete katılan meslek mensuplarının çoğunluğunun gizlilikten yana görüş bildirdiğini belirtmişlerdir. Bekçi ve Bitlisli (2012), çalışmalarında ankete verilen cevapların ortalamasını 3,8595 olarak bulmuştur. Muhasebe meslek mensuplarının şeffaflık eğilimi içinde olduklarını belirtmiştir. Durmuş ve Güneş (2017), çalışmalarında, meslek mensuplarının çoğunlukla şeffaflıktan yana olduklarını belirtmişlerdir.

$\mathrm{Bu}$ çalışmalar esas alındığında Türkiye'deki muhasebe kültürünün büyük ölçüde profesyonellikten, tekdüzelikten, tutuculuktan ve şeffaflıktan yana bir eğilim içinde olduğu yorumu yapılabilmektedir.

\section{ARAŞTIRMA}

Uluslararas1 Entegre Raporlama Komitesi tarafindan 2013 yılında yayınlanan Uluslararası Entegre Raporlama Çerçevesinin Gray'in muhasebe değerleriyle benzer yanları bulunmaktadır. $\mathrm{Bu}$ benzerliklere ayrıntılı olarak aşağıda yer verilmiştir.

\section{Kısıtları ve Önermeleri}

\subsection{Araştırmanın Konusu, Amacı,}

Araştırma Uluslararası Entegre Raporlama Çerçevesini ve muhasebe kültürü değerlerini konu almaktadır. Araştırmanın amacı, Uluslararası Entegre Raporlama Çerçevesinin muhasebe kültürü değerlerine eğilimi üzerine önermelerde bulunmak ve bu önermeleri güçlendirmektir. Araștırma Uluslararası Entegre Raporlama Çerçevesi ve Gray'in muhasebe kültürü değerleri ile sınırlandırılmıștır.

Yeloğlu (2011), çalışmasında Türk toplumsal kültürünün örgüt yapılarına yansımasını incelemiştir. Bu çalışma Hofstede'nin kültür ve Mintzberg'in yapı değişkenlerini ele almıştır. Ele alınan değişkenlere ilişkin bir ilişki ağı kurulmuş ve her ilişkiye yönelik önermelerde bulunulmuştur.

$\mathrm{Bu}$ çalışmadan yola çıkarak, Uluslararası Entegre Raporlama Çerçevesinin muhasebe kültürü değerlerine eğilimi üzerine önermeler ileri sürülmeye çalışılmıştır. Uluslararası Entegre Raporlama Çerçevesinin Gray'in muhasebe değerlerine benzer yanları vardır. Bu benzerlikler ve literatür taramasının da yardımıyla bulgular elde edilmiş ve bu bulgular sayesinde her muhasebe değerine yönelik önermelerde bulunulmuştur.

Araştırma önermelerinde bağımsız değişkenler muhasebe kültürü değerleri iken bağımlı değişken Uluslararası Entegre Raporlama Çerçevesine uyum düzeyidir. Araştırmanın önermeleri aşağıda yer almaktadır.

Önerme 1.a: Uluslararası Entegre Raporlama Çerçevesi profesyonellik muhasebe kültür değerine daha yatkındır. 
Önerme 1.b: Uluslararası Entegre Raporlama Çerçevesi statükoculuk muhasebe kültür değerine daha yatkındır.

Önerme 2.a: Uluslararas1 Entegre Raporlama Çerçevesi esneklik muhasebe kültür değerine daha yatkındir.

Önerme 2.b: Uluslararası Entegre Raporlama Çerçevesi tekdüzelik muhasebe kültür değerine daha yatkındır.

Önerme 3.a: Uluslararası Entegre Raporlama Çerçevesi tutuculuk muhasebe kültür değerine daha yatkındır.

Önerme 3.b: Uluslararası Entegre Raporlama Çerçevesi iyimserlik muhasebe kültür değerine daha yatkındır.

Önerme 4.a: Uluslararas1 Entegre Raporlama Çerçevesi şeffaflık muhasebe kültür değerine daha yatkındır.

Önerme 4.b: Uluslararası Entegre Raporlama Çerçevesi gizlilik muhasebe kültür değerine daha yatkındır.

5.2. Uluslararast Entegre Raporlama Çerçevesinde Statükoculuk Yerine Profesyonellik

Uluslararası Entegre Raporlama Çerçevesi temel kavramlar, kılavuz ilkeler ve içerik öğeleri başlıklarından oluşmaktadır. Bu başlıklar altında ele alınan ifadeler ve Gray'in muhasebe kültürü değerleri göz önünde bulundurulduğunda, aşağıdaki önermeleri öne sürmek mümkündür.

Önerme 1.a: Uluslararası Entegre Raporlama Çerçevesi profesyonellik muhasebe kültür değerine daha yatkındır.

Önerme 1.b: Uluslararası Entegre Raporlama Çerçevesi statükoculuk muhasebe kültür değerine daha yatkındır.

Statükoculuk/Profesyonellik ile Uluslararası Entegre Raporlama Çerçevesi uyum düzeyi bu şekilde önerilmiştir. Yapılan inceleme sonucunda Uluslararası Entegre Raporlama Çerçevesinin profesyonellik ile on üç maddesi, statükoculuk ile üç maddesi yakın görülmüştür. Uluslararası Entegre Raporlama Çerçevesinin Gray'in muhasebe kültürü değerlerinden profesyonellikle daha fazla benzer yanları bulunmaktadır. Önermeleri güçlendirmek adına aşağıdaki incelemeler yapılmış ve bu benzerliklere ayrıntılı olarak yer verilmiştir.

\subsubsection{Uluslararasi Entegre Raporlama Çerçevesinde Statükoculuk Değeri \\ Gray'in statükoculuk-profesyonellik muhasebe değerlerine göre incelendiği zaman Uluslararası Entegre Raporlama Çerçevesinin} statükoculuktan yana bir eğilim içinde olmadığ yorumu yapılabilmektedir. Uluslararası Entegre Raporlama Çerçevesinin statükoculuk ile üç maddesi yakın görülmüştür. Statükoculuk değerine yakın görülen az sayıdaki Uluslararası Entegre Raporlama Çerçevesi maddelerine ve bu maddelerin yakın görülme nedenlerine aşağıda ayrıntılı olarak yer verilmiştir.

"Sermaye öğeleri başka taraflara aitse ya da bunların bir sahibi yoksa gözetme sorumluluğu kanun veya yönetmelikler (örneğin sermaye ögelerinin sahipleriyle yapulan sözleşmeler, çalışma kanunları veya çevre koruma yönetmelikleri) yoluyla yüklenebilir" (IIRC, 2013: 18). Paydaşlarla ilişkiler başlığ1 altında yer alan bu ifadedeki gözetleme sorumluluğunun kanun veya yönetmelikler yoluyla yüklenebilmesi kısmı statükoculuk değerine yakın görülmüştür.

"Performans açılamalarında yönetmeliklerin performans üzerinde önemli etkisi olan durumlar (örneğin yasal fiyat düzenlemesi nedeniyle gelirlerin sinırlanmasi) veya kuruluşun kanun veya yönetmeliklere uymamasinın faaliyetlerini önemli ölçüde etkileyebileceği hususuna da yer verilebilir" (IIRC, 2013: 28). Performans başlı̆̆1 altında yer alan bu ifadedeki yönetmeliklerin performans üzerinde etkisi olan durumlara yer verilebilir kısmı statükoculuk değerine yakın görülmüștür.

"Bir kuruluşun genel görünüşü hakkında bir entegre raporda yapılacak açıklamalar, kuruluşun tabi olduğu yasal veya düzenleyici gereklilikleri dikkate alarak yapılır" (IIRC, 2013: 29). Genel görünüş başlığı altında yer alan bu ifadedeki yasal veya düzenleyici gerekliliklerin dikkate alınması bölümü statükoculuk değerine yakın görülmüştür.

\subsubsection{Uluslararast Entegre Raporlama} Çerçevesinde Profesyonellik Değeri

Gray'in statükoculuk-profesyonellik muhasebe değerlerine göre incelendiği zaman Uluslararası Entegre Raporlama Çerçevesinin çoğu maddesinin profesyonellikten yana bir eğilim içinde olduğu yorumu yapilabilmektedir. Uluslararas1 Entegre Raporlama Çerçevesinin profesyonellik ile on üç maddesi yakın görülmüștür. Profesyonellik değerine yakın görülen Uluslararası Entegre Raporlama Çerçevesi maddelerine ve bu maddelerin yakın görülme nedenlerine aşağıda ayrıntılı olarak yer verilmiştir.

"International Integrated Reporting Council (Uluslararasl Entegre Raporlama Konseyi-IIRC), düzenleyici kurumlar, yatırımcilar, şirketler, standart belirleme otoriteleri, muhasebe uzmanlart ve STK'lar tarafindan kurulmuş küresel bir koalisyondur" (IIRC, 2013: 1). IIRC hakkında başlığı altında yer alan bu ifadede Uluslararası Entegre Raporlama Çerçevesini hazırlayan kuruluşun küresel bir koalisyon olması profesyonellik değerine yakın görülmüştür.

"Bu rapor, uyum sağlama ya da açılama temelinde geçiş dönemi ile ilgili olarak rapor için sorumluluğu üstlenen, kurumsal yönetim sorumlularına ait bir beyanat içermelidir" (IIRC, 2013: 4). Bir entegre rapor başlığı altında yer alan bu ifadedeki kurumsal yönetim sorumlularına ait bir 
beyanat içermesi kısmı profesyonellik değerine yakın görülmüştür.

"Bir entegre rapor çalışanlar, müşteriler, tedarikçiler, iş ortaklarl, yerel toplumlar, yasa koyucular, düzenleyiciler ve politika yapıcilar dahil olmak üzere bir şirketin zaman içinde değer yaratma kabiliyeti üzerinde etkisi olan tüm paydaşlardan faydalanır" (IIRC, 2013: 7). Bir entegre raporun amacı ve kullanıcıları başlığı altında yer alan bu ifadedeki entegre raporun tüm paydaşlardan faydalanma kısmı profesyonellik değerine yakın görülmüştür.

"Bilgiler arası bağlantı için kullanılan başlıca biçimler aşağıdaki öğeler arasındaki bağlantıları içerir: Yönetim bilgileri, yönetim kurulu bilgileri ve kuruluş dışından rapor edilen bilgiler. Örneğin, paragraf 4.53'te belirtildiği gibi bir entegre raporda kullanılan nicel bilgilerin, kurumsal yönetim sorumlular tarafindan kurulus içinde kullanilan göstergelerle tutarlı olması önemlidir" (IIRC, 2013: 16). Bilgiler arası bağlantı başlığı altında yer alan bu ifadedeki yönetim kurulu bilgileri ve kurulu dişından rapor edilen bilgiler kısmı profesyonellik değerine yakın görülmüştür.

"Yasal bir gözetim sorumluluğu yoksa kuruluş, gözetim sorumluluklarını kabul etmeye yönelik etik sorumluluğa sahip olabilir veya bunlar kabul etmeyi seçebilir ve paydaşların beklentilerine göre bu sorumluluğunu yerine getirir" (IIRC, 2013: 18). Paydaşlarla ilişkiler başlığg altında yer alan bu ifadedeki yasal bir gözetim sorumluluğu olmamasına rağmen etik sorumluluğa sahip olabilme vurgusu profesyonellik değerine yakın görülmüsstür.

"Normalde, de ğer yaratma ile ilgili olup kurumsal yönetim sorumluları ile yapılan toplantılarda tartışılan konular ilgili olarak kabul edilir. Illgili konuların belirlenmesinde başlıca paydaşların bakış açılarının ne olduğunu anlamak önemlidir" (IIRC, 2013: 19). İlgili konuların belirlenmesi başlığ altında yer alan bu ifadedeki başlıca paydaşların bakış açılarının ne olduğunu anlama kısmı profesyonellik değerine yakın görülmüştür.

"Maddi konular hakkında açıklanacak bilgileri belirlerken çok iyi muhakeme edilmesi gerekir. Bunun için hem iç hem diş bakış açılarından yararlanilvr ve entegre raporun paragraf 1.7 'de açıklanan asıl amacını karşılayabilmesi için finansal sermaye sağlayan taraflarla ve diğer taraflarla düzenli etkileşim kurulması gerekir" (IIRC, 2013: 19). Açıklanacak bilgilerin belirlenmesi başlığı altında yer alan bu ifadedeki finansal sermaye sağlayan taraflarla ve diğer taraflarla düzenli etkileşim kurulması kısmı profesyonellik değerine yakın görülmüştür.

"Finansal raporlama yapan kuruluşun raporlama sinirinin merkezinde olmasinin nedeni: Finansal sermaye sağlayan tarafların yatırım yaptığ ve dolaylstyla hakkinda bilgi almasi gereken alan finansal raporlama yapan kuruluştur" (IIRC, 2013: 19). Raporlama sınırı başlığı altında yer alan bu ifadedeki finansal raporlama yapan kuruluşun raporlama sinırının merkezinde olması kısmı profesyonellik değerine yakın görülmüştür.

"Finansal raporlama yapan kuruluş hangi bağlı kuruluşların, ortak girişimlerin veya iştiraklerin işlemlerinin ve ilgili olaylarının kuruluşun mali durum raporuna dahil edileceğini belirler. Finansal raporlama yapan kuruluş, kontrol veya önemli etki kavramlarina göre şekillenen finansal raporlama standartlarina göre belirlenir" (IIRC, 2013: 20). Finansal raporlama yapan kuruluş başlığ alan bu ifadedeki kuruluşun finansal raporlama standartlarına göre belirlenmesi kısmı standartlar komite tarafından hazırlandığ 1 için profesyonellik değerine yakın görülmüştür.

"Kurumsal yönetim sorumlular kuruluşun stratejisinin, kurumsal yönetiminin, performansinin ve beklentilerinin zaman içinde değer yaratmayla nasıl sonuçlanacağını belirlemede nihai sorumluluğa sahiptir. Bunlar, süreçte aktif rol alan çalışanların belirlenmesi ve yönetilmesi dahil olmak üzere bir entegre raporun hazırlanması ve sunulması açısından etkili liderlik ve karar verme kabiliyetlerinin sergilenmesini sağlamaktan sorumludur" (IIRC, 2013: 21). Güvenilirlik başlığ 1 altında yer alan bu ifadedeki kurumsal yönetim sorumlularının sorumlulukları kısmı profesyonellik değerine yakın görülmüştür.

"Bir entegre rapor hazırlanırken bir denetim düzeni oluşturulması üst düzey yönetime ve kurumsal yönetim sorumlularina raporu incelemede ve bilgilerin rapora dahil edilmeye yeterli ilgiye sahip olup olmadığını belirlemede yardımcı olur. Bazı durumlarda (örneğin geleceğe yönelik bilgiler açısından) bir entegre raporun güvenilirliği sağlamak için kullanılan mekanizmaları açıklaması gerekebilir" (IIRC, 2013: 21). Güvenilirlik başlığı altında yer alan bu ifadedeki entegre raporun güvenilirliği sağlamak için kullanılan mekanizmaların açıklaması kısmı profesyonellik değerine yakın görülmüştür.

"Eksiksiz bir raporda hem pozitif hem negatif tüm gerekli bilgiler yer alır" (IIRC, 2013: 22). Eksiksizlik başlığ 1 altında yer alan bu ifadedeki aynı sektördeki kuruluşların hangi konular hakkında raporlama yaptığının göz önünde bulundurulması kısmı profesyonellik değerine yakın görülmüştür.

"Bir entegre raporda normalde zaman içinde beklenen değişiklikler vurgulanır ve aşağıdaki hususlar hakkında yapılan güvenilir ve şeffaf analizlerle elde edilen bilgiler sağlanır: Kuruluşun kisa, orta ve uzun vadede diş çevresinde karşılaşması muhtemel durumlar hakkındaki beklentileri. Bunun kuruluşu nasıl etkileyeceği. Kuruluşun halihazırda karşısına çıkması muhtemel kritik zorluklara ve 
belirsizliklere yanıt vermek için nasıl teşkilatlandı ̆̆ $\imath$ ", (IIRC, 2013: 28). Genel görünüş başlığ1 altında yer alan bu ifadedeki güvenilir ve şeffaf analizlerle elde edilen bilgiler kısmı profesyonellik değerine yakın görülmüștür.

\subsection{Uluslararasi Entegre Raporlama} Çerçevesinde Tekdüzelik Yerine Esneklik

Temel kavramlar, kılavuz ilkeler ve içerik öğeleri başlıklarından oluşan Uluslararası Entegre Raporlama Çerçevesindeki ifadeler ve Gray'in muhasebe kültürü değerleri göz önünde bulundurulduğu zaman aşağıdaki önermeleri sunmak mümkün olacaktır.

Önerme 2.a: Uluslararas1 Entegre Raporlama Çerçevesi esneklik muhasebe kültür değerine daha yatkındır.

Önerme 2.b: Uluslararası Entegre Raporlama Çerçevesi tekdüzelik muhasebe kültür değerine daha yatkındır.

Tekdüzelik/Esneklik ile Uluslararası Entegre Raporlama Çerçevesi uyum düzeyi bu şekilde önerilmiştir. Yapılan inceleme sonucunda Uluslararası Entegre Raporlama Çerçevesinin esneklik ile on iki maddesi, tekdüzelik ile on maddesi yakın görülmüştür. Uluslararası Entegre Raporlama Çerçevesinin Gray'in muhasebe değerlerinden hem tekdüzelik hem de esneklikle benzer yanları bulunmaktadır. Fakat az farkla da olsa esneklikten yana bir eğilim içinde olduğu söylenebilir. Önermeleri güçlendirmek adına aşağıdaki incelemeler yapılmış ve bu benzerliklere ayrıntılı olarak yer verilmiştir.

\section{Çerçevesinde Tekdü̈zelik Değeri}

5.3.1. Uluslararast Entegre Raporlama

Gray'in tekdüzelik-esneklik muhasebe değerlerine göre incelendiği zaman Uluslararası Entegre Raporlama Çerçevesinin hem tekdüzelikten hem de esneklikten yana bir eğilim içinde olduğu yorumu yapılabilmesine rağmen az farkla da olsa tekdüzelikten yana bir eğilim içinde olmadığ 1 söylenebilir. Uluslararas1 Entegre Raporlama Çerçevesinin tekdüzelik ile on maddesi yakın görülmüştür. Tekdüzelik değerine yakın görülen sayıca daha az olan Uluslararası Entegre Raporlama Çerçevesi maddelerine ve bu maddelerin yakın görülme nedenlerine aşağıda ayrıntılı olarak yer verilmiştir.

"Tutarlılık ve karşılaştırabilirlik: Bir entegre rapordaki bilgiler: (a) zaman içinde tutarlı bir temele dayall olarak ve (b) kuruluşun kendi zaman içinde değer yaratma kabiliyeti açısından, diğer kuruluşlarla karşılaştırılmasina olanak sağlayacak şekilde sunulmalıdır" (IIRC, 2013: 5). Kilavuz ilkeler başlığ1 altında yer alan bu ifadedeki entegre raporun diğer kuruluşlarla karşılaştırılacak şekilde sunulması kısmı tekdüzelik değerine görülmüştür.

"Bir entegre rapor bu Çerçeveye göre hazlrlanmalıdır" (IIRC, 2013: 7). Entegre rapor tanımı başlığı altında yer alan bu ifadedeki çerçeveye göre hazırlanma vurgusu tekdüzelik değerine yakın görülmüştür.

"Bir entegre rapor olduğu iddia edilen ve Çerçeveye atıfta bulunan bildirimlerde, aksi belirtilmedikçe kalın italik harflerle belirtilen tüm gereksinimler uygulanmalıdır" (IIRC, 2013: 8). Çerçevenin uygulanışı başlığı altında yer alan kalın harflerle belirtilen gereksinimlerin hepsinin uygulanma vurgusu tekdüzelik değerine yakın görülmüştür.

"Bir entegre raporda kurumsal yönetim sorumluları hakkında aşağıdakiler dahil olmak üzere bir beyanat yer almalıdır: Entegre raporun bütünlüğ̈̈nü sağlamak için bu kişilerin sorumluluğuna ilişkin bir onay. Bu kişilerin entegre raporun hazırlanmasında ve sunulmasinda müsterek akıl kullandıklarına ilişkin bir onay" (IIRC, 2013: 9). Bir entegre raporla ilgili sorumluluk başlığı altında yer alan bu ifadedeki onay vurgusu tekdüzelik değerine yakın görülmüştür.

"Bir kuruluşun sermaye öğelerini kendi amaçlar doğrultusunda nasil kategorize ettiğine bakilmaksizin paragraf 2.15'te tanımlanan kategoriler, kuruluşun kullandiğ veya etkilediği bir sermaye öğesini atlamamasını sağlamaya yönelik kllavuz bilgi olarak kullanılmalıdır" (IIRC, 2013: 12). Sermaye öğelerinin çerçevedeki rolü başlığ 1 altında yer alan bu ifadedeki kılavuz bilgi olarak kullanılma kısmı tekdüzelik değerine yakın görülmüștür.

"Bir entegre rapor kuruluşun stratejisi ve bunun, kuruluşun kisa, orta ve uzun vadede değer yaratma kabiliyetiyle ve sermaye öğelerini kullanımı ve etkileşimiyle nasil bir ilgisi olduğu hakkında bilgi sağlamalıdır" (IIRC, 2013: 16). Stratejik odak ve geleceğe yönelim başlığ altında yer alan bu ifadedeki kuruluşun stratejisi hakkında bilgi sağlamalı kısmı tekdüzelik değerine yakın görülmüştür.

"Manttklı bir yapıya sahip olmast, iyi sunulmasl, net ifadelerle yazılması, anlaşılır ve mesleki jargon içermeyen dil kullanılması ve net bir şekilde betimlenen (ve bağlantı verilen) bölümler ve çapraz başvurular gibi etkili gezinme araçları kullanılması halinde bilgiler arası bağlantılar ve bir entegre raporun genel anlamda kullanışlılı̆̆ daha da güçlenecektir. Bu bağlamda bilgiler açısından arama, erişim, birleştirme, bağlantı kurma, kişiselleştirme, tekrar kullanma veya analiz etme kabiliyetini artırmak için bilgi ve iletişim teknolojisi kullanılabilir" (IIRC, 2013: 17). Bilgiler aras1 bağlantı başlığı altında yer alan bu ifadedeki, entegre raporun genel anlamda kullanışlılığını daha da güçlendirmemek adına bilgi ve iletişim teknolojisi kullanılabilmesi kısmı tekdüzelik değerine yakın görülmüştür.

"Finansal raporlama yapan kuruluş hangi bağlı kuruluşların, ortak girişimlerin veya iştiraklerin 
işlemlerinin ve ilgili olaylarının kuruluşun mali durum raporuna dahil edileceğini belirler. Finansal raporlama yapan kurulus, kontrol veya önemli etki kavramlarina göre şekillenen finansal raporlama standartlarına göre belirlenir" (IIRC, 2013: 20). Finansal raporlama yapan kuruluş başlığı altında yer alan bu ifadedeki kuruluşun finansal raporlama standartlarına göre belirlenmesi kısmı tekdüzelik değerine yakın görülmüştür.

"Rapordaki bilgilerin kalitesini artırmak için bir değişiklik gerekmedikçe raporlama ilkeleri birbirini takip eden dönemlerde tutarl ssekilde izlenmelidir" (IIRC, 2013: 23). Tutarlılık başlığ1 altında yer alan bu ifadedeki raporlama ilkelerinin birbirini izleyen dönemlerde tutarlı olması kısmı tekdüzelik değerine yakın görülmüştür.

"Bir entegre raporda iş modeli aşağıdaki temel ögelerle birlikte tanımlanır: Girdiler, iş faaliyetleri, çıktılar, sonuçlar" (IIRC, 2013: 25). İş modeli başlığı altında yer alan bu ifadedeki iş modelinin temel öğelerle birlikte tanımlanma kısmı tekdüzelik değerine yakın görülmüştür.

\subsubsection{Uluslararast Entegre Raporlama Çerçevesinde Esneklik Değeri \\ Gray'in tekdüzelik-esneklik muhasebe} değerlerine göre incelendiği zaman Uluslararas1 Entegre Raporlama Çerçevesinin hem tekdüzelikten hem de esneklikten yana bir eğilim içinde olduğu yorumu yapılabilmesine rağmen az farkla da olsa esneklikten yana bir eğilim içinde olduğu söylenebilir. Uluslararası Entegre Raporlama Çerçevesinin esneklik ile on iki maddesi yakın görülmüsstür. Esneklik değerine yakın görülen sayıca daha fazla Uluslararası Entegre Raporlama Çerçevesi maddelerine ve bu maddelerin yakın görülme nedenlerine aşağıda ayrıntılı olarak yer verilmiştir.

"Entegre rapor hazırlama isteğinde olan şirketler ve diğer kuruluşlar için ilkelere dayalı bir kılavuz olan Uluslararası $\langle E R>$ Çerçevesinin, söz konusu bireysel girişimleri hizlandırması ve raporlama sürecinin kendisi dahil olmak üzere $<I R>$ uygulamasinın faydalarını ortaya koymak üzere dünya çapında kurumsal raporlama alanında yapılacak daha büyük yeniliklere ivme kazandırması amaçlanmaktadır" (IIRC, 2013: 2). Entegre raporlama hakkında başlığı altında yer alan bu ifadedeki ilkelere dayalı bir k1lavuz olma kısm1 esneklik değerine yakın görülmüştür.

"Sermaye ögeleri, kuruluşun faaliyetleri ve sonuçlart ile artan, azalan ya da dönüşü̈rülen bir değerler stoğudur. Bunlar bu Çerçevede finansal, üretilmiş, fikri, insan kaynakları, sosyal, iliskisel ve doğal sermaye ögeleri olarak siniflandırılmıștır ancak entegre rapor düzenleyen kuruluşların bu sinıflandırmayı kullanmasi ya da raporlarını bunlara göre düzenlemesi gerekmemektedir" (IIRC, 2013: 4). Temel kavramlar başlı̆̆ 1 altında yer alan bu ifadedeki entegre raporun çerçevedeki sermaye öğelerini kullanması gerekmemektedir kısmı esneklik değerine yakın görülmüştür.

"Bu rapor spesifik temel performans göstergeleri, ölçüm yöntemleri ya da farklı konular hakkında açıklamalar sağlamaz; ancak, bir entegre raporun Çerçeve ile uyumlu olduğunu söyleyebilmek için öncesinde uygulanması gereken az sayldaki bazı gereksinimleri içerir" (IIRC, 2013: 4). Bir entegre rapor başlığı altında yer alan bu ifadedeki az sayıda gereksinimleri içerme kısmı esneklik değeriyle yakın görülmüştür.

"Bu Çerçeve ilkelere dayalıdır. Ilkelere dayalı yaklaşımın amacı esneklik ve düzen arasında, farklı kuruluşların kendilerine özgü koşulları arasındaki büyük farklılıkları dikkate alarak ilgili bilgiye duyulan ihtiyacı karşılamak üzere kuruluşlar arasında yeterli bir karşılaştırılabilirlik seviyesi oluşturmaya yönelik bir denge sağlamaktır" (IIRC, 2013: 7). İlkelere dayalı bir yaklaşım başlığı altında yer alan bu ifadedeki esneklik ve düzen arasında bir denge sağlama kısmı esneklik değerine yakın görülmüştür.

"Bu çerçeve asıl olarak özel sektördeki her ölçekten kar amaçlı şirketlere yönelik olarak yazılmış olmakla birlikte gereken uyarlamalarla birlikte kamu sektöründe veya kar amacl gütmeyen özel kuruluşlar tarafindan da kullanilabilir" (IIRC, 2013: 7). Çerçevenin amacı başlı̆̆ 1 altında yer alan bu ifadedeki çerçevenin farklı kesimlere yönelik olması kısmı esneklik değerine yakın görülmüştür.

"Bir entegre rapor mevcut uyumluluk gereksinimlerine yanıt olarak hazırlanabilir. Örneğin yerel kanunlar bir kuruluşun mali durum tablolarina ilişkin bağlam săglayan bir yönetim yorumu ya da başka bir rapor hazırlamasını gerektirebilir. Bu durumda hazırlanacak olan rapor Çerçeveye göre hazırlanmast halinde bir entegre rapor olarak kabul edilebilir. Raporda bu Çerçevenin gerektirdikleri dişında bir bilgi yer alması gerekiyorsa söz konusu diğer bilgilerin bu Çerçeveyle istenen kisa ve öz bilgileri engellememesi halinde rapor, entegre rapor olarak kabul edilebilir" (IIRC, 2013: 8). Rapor biçimi ve diğer bilgilerle ilişkiler başlığı altında yer alan bu ifadelerdeki hazırlanan diğer raporların da entegre rapor olarak kabul edilebilmesi kısmı esneklik değerine yakın görülmüştür.

"Tüm kuruluşların başarlya ulaşması çeşitli sermaye ögelerine dayalıdır. Bu çerçevede sermaye ögeleri finansal, üretilmiş, fikri, insan kaynaklart, sosyal, ilişkisel ve doğal sermaye öğeleri olarak siniflandırılmıştır ancak paragraf 2.17-2.19'da da ele alındığ gibi entegre rapor düzenleyen kuruluşların bu sinıflandırmayı kullanması şart değildir" (IIRC, 2013: 11). Sermaye stokları ve akışı başlığ altında yer alan bu ifadedeki sınıflandırmanın kullanımının şart olmaması kısmı esneklik değerine yakın görülmüştür. 
"Kuruluşlar bir değer yaratma amacında olmasına rağmen bunun için bazı sermaye öğelerinde sakl değerin azalmasl ve dolaylslyla toplam sermaye stoğunda net bir azalma yaşanmasi gerekebilir. Birçok durumda net etkinin bir artış veya azalma (ya da değerin korunmasi) şeklinde görülüp görülmeyeceği seçilen bakış açısına bă̆lıdır” (IIRC, 2013: 11). Sermaye stokları ve akışı başlığı altında yer alan net etkinin artış, azalış ya da değerinin korunmasının seçilen bakış açısına bağlı olması kısmı esneklik değerine yakın görülmüştür.

"Kuruluşlar sermaye öğelerini farklı şekilde kategorize edebilir. Örneğin, dış paydaşlarla olan ilişkiler ve marka ve itibar ile ilişkili maddi olmayan varliklar (her ikisi de paragraf 2.15'te sosyal ve ilişkisel sermaye öğesi olarak tanımlanmıştır) bazı kuruluşlar tarafindan ayri sermaye öğeleri, başka sermaye öğelerinin bileşenleri ya da farkl sermaye öğelerinin dă̆ınık parçaları olarak kabul edilebilir. Aynı şekilde bazı kuruluşlar, fikri sermaye öğesini insan, "yapısal" ve "ilişkisel" sermayelerden oluşan bir sermaye ögesi olarak tanımlayabilir" (IIRC, 2013: 12). Sermaye öğelerinin çerçevedeki rolü başlığı altında yer alan bu ifadedeki sermaye öğelerinin farklı şekilde kategorize edilebilmesi kısmı esneklik değerine yakın görülmüştür.

"Bir entegre rapor, başlica paydaşlarm meşru ihtiyaç ve isteklerinin nasıl anlaşıldı̆̆ını, dikkate alındığını ve alınan kararlar, yapılan işler, performans ve sürekli iletişim yoluyla nasıl karşılandığını açıklayarak, güven ve esneklik oluşturmada çok önemli rol oynayan şeffafliğl ve hesap verebilirliği güçlendirir" (IIRC, 2013: 18). Paydaşlarla ilişkiler başlığı altında yer alan bu ifadedeki entegre raporun esneklik oluşturmada önemli rol oynayan şeffaflığ 1 ve hesap verilebilirliği güçlendirmesi kısmı esneklik değerine yakın görülmüştür.

"Her kurulus değer yaratırken kendine özgü bir yol izlediğinden, bir entegre rapordaki spesifik bilgilerin kuruluştan kuruluşa farklllık göstermesi gerekir" (IIRC, 2013: 23). Karşılaştırılabilirlik başlığ1 altında yer alan bu ifadedeki spesifik bilgilerin farklı gösterilmesi kısmı esneklik değerine yakın görülmüştür.

"Birden fazla is kolunda faaliyet gösteren bir kuruluşun entegre raporunda karmaşıklığ azaltmak için bir denge açılkaması yer almalıdır ancak maddi öneme sahip bilgiler kesinlikle atlanmamalıdır. Kurumsal yönetim sorumlularına düzenli olarak rapor edilen bilgilerin en üst düzeyi dikkate alınarak dış ve iç raporların birbirlerine uyumlu hale getirilmesi genellikle uygun kabul edilir" (IIRC, 2013: 27). Birden fazla iş modeli olan kuruluşlar başlığı altında yer alan bu ifadedeki entegre raporda karmaşıklığ 1 azaltmak için bir denge açıklamasının yer alması kısmı esneklik değerine yakın görülmüştür.

\subsection{Uluslararasi Entegre Raporlama Çerçevesinde Tutuculuk Yerine İyimserlik}

Uluslararas1 Entegre Raporlama Çerçevesinde yer alan ifadeleri ve Gray'in muhasebe kültürü değerlerini göz önünde bulundurarak aşağıdaki şekilde önermeler sunulabilir.

Önerme 3.a: Uluslararas1 Entegre Raporlama Çerçevesi tutuculuk muhasebe kültür değerine daha yatkındır.

Önerme 3.b: Uluslararas1 Entegre Raporlama Çerçevesi iyimserlik muhasebe kültür değerine daha yatkındır.

Tutuculuk/Iyimserlik ile Uluslararası Entegre Raporlama Çerçevesi uyum düzeyi bu şekilde önerilmiştir. Yapılan inceleme sonucunda Uluslararası Entegre Raporlama Çerçevesinin tutuculuk ile on bir maddesi, iyimserlik ile on maddesi yakın görülmüştür. Uluslararası Entegre Raporlama Çerçevesinin Gray'in muhasebe değerlerinden tutuculuk ile daha fazla benzer yanları bulunmaktadır. Önermeleri güçlendirmek adına aşağıdaki incelemeler yapılmış ve bu benzerliklere ayrıntılı olarak yer verilmiştir.

\subsubsection{Uluslararasi Entegre Raporlama Çerçevesinde Tutuculuk Değeri}

Gray'in tutuculuk-iyimserlik muhasebe değerlerine göre incelendiği zaman Uluslararası Entegre Raporlama Çerçevesinin hem tutuculuktan hem de iyimserlikten yana bir eğilim içinde olduğu yorumu yapılabilmesine rağmen az farkla da olsa tutuculuktan yana bir eğilim içinde olduğu söylenebilir. Uluslararası Entegre Raporlama Çerçevesinin tutuculuk ile on bir maddesi yakın görülmüştür. Tutuculuk değerine yakın görülen sayıca daha fazla Uluslararası Entegre Raporlama Çerçevesi maddelerine ve bu maddelerin yakın görülme nedenlerine aşağıda ayrıntılı olarak yer verilmiştir.

"Finansal sermaye săglayan taraflar kuruluşun kendisi için yarattığ değerle ilgilenir. Ayrıca, kuruluşun diğer taraflar için yarattı̆̆ değer kuruluşun kendisi için değer yaratma kabiliyetini etkiliyorsa veya kuruluşun belirli bir amactyla (örneğin açık bir sosyal amaç) ilgiliyse kendi değerlendirmelerine göre bu değerle de ilgilenirler" (IIRC, 2013: 10). Kuruluş ve diğerleri için değer yaratma başlı̆g 1 altında yer alan bu ifadedeki Finansal sermaye sağlayan tarafların kuruluşun kendisi için yarattığ 1 değerle ilgilenmesi kısmı tutuculuk değerine yakın görülmüştür.

"Kuruluşun stratejisi kuruluşun riskleri azaltır veya yönetirken ve firsatlart en üst düzeye çıkarırken nasıl bir yol izleyeceğini belirler. Stratejik hedefleri ve bunlara ulaşmak için kaynak aktarımı planlart yoluyla uygulamaya konan stratejileri belirler" (IIRC, 2013: 14). Değer yaratma süreci başlığ1 altında yer alan bu ifadedeki kuruluş stratejisinin kuruluşun risklerini azaltır veya 
yönetirken nasıl bir yol izleneceğini belirleme kısmı tutuculuk değerine yakın görülmüştür.

"Bu Kılavuz Illkelerin uygulanışı 4E Strateji ve kaynak aktarımı ve $4 G$ Genel Görünüs olarak adlandırılan İçerik Öğeleri ile sınırlı değildir. Başka içeriklerin seçilmesi ve sunulması için rehberlik eder ve aşağıdaki konuları içerebilir: Kuruluşun pazardaki konumunu ve iş modelini etkileyen önemli risklerin, firsatların ve bağımlılıkların vurgulanması. Kurumsal yönetim sorumlularının aşağıdaki konular hakkındaki görüşleri: Geçmiş ve gelecek performans arasındaki ilişki ve bu ilişkiyi değiştirebilecek faktörler. Kuruluşun kisa, orta ve uzun vadedeki çıkarları arasında nasil denge kurduğu. Kuruluşun gelecekteki stratejik yönünü belirlerken geçmiş deneyimlerinden neler ögrendiği” (IIRC, 2013: 16). Stratejik odak ve geleceğe yönelim başlığ kuruluşun pazardaki konumunu ve iş modelini etkileyen önemli risklerin, firsatların ve bağımlılıkların vurgulanması ve kuruluşun gelecekteki stratejik yönünü belirlerken geçmiş deneyimlerinden neler öğrendiği kısımları tutuculuk değerine yakın görülmüştür.

"Bilgiler arası bağlantı için kullanılan başlıca biçimler aşağıdaki öğeler arasındaki bağlantıları içerir: Yönetim bilgileri, yönetim kurulu bilgileri ve kuruluş dişından rapor edilen bilgiler. Örneğin, paragraf 4.53 'te belirtildiği gibi bir entegre raporda kullanılan nicel bilgilerin, kurumsal yönetim sorumluları tarafindan kuruluş içinde kullanılan göstergelerle tutarlı olması önemlidir" (IIRC, 2013: 17). Bilgiler arası bağlantı başlığı altında yer alan bu ifadedeki kullanılan göstergelerle tutarlı olması kısmı tutuculuk değerine yakın görülmüştür.

"Tüm ilgili konular önemli olarak kabul edilmez. Bir konunun entegre rapora dahil edilmesi için değer yaratma üzerindeki bilinen veya potansiyel etkisi bakımından yeterince önemli olmasi gerekir. Bunun için konunun etkisinin ne derece büyük olduğu ve gerçekleşip gerçekleşmeyeceği belirsizse meydana gelme olasilı̆̆ de gerlendirilmelidir" (IIRC, 2013: 19). Önemin değerlendirilmesi başlığı altında yer alan bu ifadedeki gerçekleşmesi belirsiz olan konuların bile meydana gelme olasılığının değerlendirilmesi vurgusu, tutuculuk değerinin olabileceğin en kötüsünü bekleme/dikkate alma özelliğine yakın görülmüştür.

"Bilgilerin güvenilirliği sahip olduğu dengeye ve maddi hata içermemesine bağlıdır. Güvenilirlik (sıklıkla aslına sadık kalma olarak da adlandırılır) katı iç denetim ve raporlama sistemleri, paydaş katılımı, iç denetim veya benzeri fonksiyonlar ile kuruluş dışından bağımsız denetim gibi mekanizmalarla artırtlır" (IIRC, 2013: 21). Güvenilirlik başlığı altında yer alan bu ifadedeki katı iç denetim ve raporlama sistemleri kısmı tutuculuk değerine yakın görülmüştür.
"Maddi hata içermeme demek bilginin her açıdan tamamen kesin olması demek değildir. Şu anlama gelir: Rapordaki bilgilerin maddi açıdan yanıltıcı olma riskini kabul edilebilir düşük bir seviyeye indirmek için süreç ve denetimler uygulanmıştır. Tahmin içeren bilgilerin net bir şekilde bildirilmesi ve tahmin süreçlerinin özellikleri ve sınırlamalarının açılanması sağlanmıştır" (IIRC, 2013: 22). Maddi hata içermeme başlığı altında yer alan bu ifadedeki, rapordaki bilgilerin maddi açıdan yanıltıc1 olma riskini kabul edilebilir düşük bir seviyeye indirmek için süreç ve denetimler uygulanma kısmı ve tahmin içeren bilgilerin net bir şekilde bildirilmesi kısmı tutuculuk değerine yakın görülmüștür.

"Bir kuruluş, rekabet avantajı ile ilgili maddi konular (örneğin kritik stratejiler) hakkındaki bilgileri rapora dahil etme sürecinde konunun özünü, rekabette önemli avantaj kaybına neden olabilecek spesifik bilgileri açığa çıkarmadan nasıl açıklayacağını göz önünde bulundurur. Kuruluş buna göre bir entegre raporda yer alan bilgilerden bir rakibinin ne tür bir kazanım sağlayacağını göz önünde bulundurur ve bunu, entegre raporun paragraf 1.7'de açılanan asıl amacını karşılaması ihtiyacına göre dengeler" (IIRC, 2013: 22). Rekabet avantajı başlığı altında yer alan bu ifadede özellikli bilgilerin açıklanması ve rakibin sağlayacağı kazanımlar, tutuculuk değerinin olabileceğin en kötüsünü bekleme/dikkate alma özelliğine yakın görülmüştür.

"Bir entegre rapordaki bilgiler: Zaman içinde tutarl bir temele dayalı olarak, kuruluşun kendi zaman içinde değer yaratma kabiliyeti açısından, diğer kuruluşlarla karşılaştırılmasına olanak sağlayacak şekilde sunulmalıdır" (IIRC, 2013: 23). Tutarlılık ve karşılaştırabilirlik başlığı altında yer alan bu ifadedeki tutarlı bir temele dayalı olarak sunulması kısmı tutuculuk değerine yakın görülmüștür.

"Rapordaki bilgilerin kalitesini artırmak için bir değişiklik gerekmedikçe raporlama ilkeleri birbirini takip eden dönemlerde tutarl şekilde izlenmelidir. Buna, raporlama dönemleri içinde maddi önem sahibi olmaya devam etmeleri halinde ayn KPI'ların rapor edilmesi dahildir. Önemli bir değişiklik gerçekleştiğinde, kuruluş değişikliğin nedenini ve etkisini açılar (ve uygulanabilir ve maddi açıdan önemliyse niceliğini bildirir)" (IIRC, 2013: 23). Tutarlılık başlığı altında yer alan bu ifadedeki raporlama ilkelerinin birbirini takip eden dönemlerde tutarlı şekilde izlenmeli kısmı tutuculuk değerine yakın görülmüştür.

"Önemlilik adll Kllavuz Ilke dikkate alındı̆̆ında kuruluşun sürekli değer yaratma kabiliyeti açısından temel önem taşıyan ya da aşırı sonuçlar doğurabilen gerçek risklere (klsa, orta veya uzun vadeli) olan yaklaşımı, bunların gerçekleşme olasılıkları çok düşük olsa da genellikle bir entegre 
rapora dahil edilir" (IIRC, 2013: 27). Riskler ve firsatlar başlığ1 altında yer alan bu ifadedeki gerçekleşme olasılığı çok düşük olan risklerin entegre rapora dahil edilmesi yaklaşımı, tutuculuk değerinin belirsizlikle başa çıkabilmek için daha ölçülü ölçüm yöntemlerini kullanma özelliğine yakın görülmüsştür.

\subsubsection{Uluslararasi Entegre Raporlama Çerçevesinde İyimserlik Değeri}

Gray'in tutuculuk-iyimserlik muhasebe değerlerine göre incelendiğ $i$ zaman Uluslararası Entegre Raporlama Çerçevesinin hem tutuculuktan hem de iyimserlikten yana bir eğilim içinde olduğu yorumu yapılabilmesine rağmen az farkla da olsa iyimserlikten yana bir eğilim içinde olmadığ 1 söylenebilir. Uluslararası Entegre Raporlama Çerçevesinin iyimserlik ile on maddesi yakın görülmüştür. İyimserlik değerine yakın görülen sayıca daha az olan Uluslararası Entegre Raporlama Çerçevesi maddelerine ve bu maddelerin yakın görülme nedenlerine aşağıda ayrıntılı olarak yer verilmiştir.

"Bir entegre raporun amacı kuruluşun herhangi bir zamandaki değerini, zaman içinde yarattı̆̆ $l$ değeri ya da tüm sermaye öğelerinin kullanımını veya bunlar üzerindeki etkilerini nicelemek veya parasallaştırmak değildir" (IIRC, 2013: 8). Nicel ve nitel bilgiler başlığı altında yer alan bu ifadedeki parasallaştırmama vurgusu iyimserlik değerine yakın görülmüştür.

"Sermaye öğeleri, kuruluşun faaliyetleri ve sonuçları ile artan, azalan ya da dönüştürülen bir değerler stoğudur. Örneğin, bir kuruluş kar yaptığında finansal sermayesi artar ve çalışanlara daha iyi eğitim verildiğinde insan sermayesi iyileşir" (IIRC, 2013: 11). Sermaye stokları ve akışı başlığ altında yer alan bu ifadedeki sermaye öğelerinin artan, azalan ya da dönüştürülen değerler stoku olması kısmı iyimserlik değerine yakın görülmüştür.

"Kuruluşlar bir değer yaratma amacında olmasına rağmen bunun için bazı sermaye öğelerinde sakl değerin azalmasl ve dolaylsiyla toplam sermaye stoğunda net bir azalma yaşanmast gerekebilir. Birçok durumda net etkinin bir artış veya azalma (ya da değerin korunması) şeklinde görülüp görülmeyeceği seçilen bakış açısına bağlıdır” (IIRC, 2013: 11). Sermaye stokları ve akışı başlığı altında yer alan net etkinin artış, azalış ya da değerinin korunmasının seçilen bakış açısına bağlanması kısmı iyimserlik değerine yakın görülmüştür.

"Bir entegre raporda konuyla daha az ilgili bilgilerin getireceği karmaşıklık olmaksızın kuruluşun stratejisini, kurumsal yönetimini, performansinı ve beklentilerini anlamak için yeterli bağlam sunulur" (IIRC, 2013: 21). Kısa ve öz olma başlığı altında yer alan bu ifadedeki yeterli bağlam sunulması k1smı iyimserlik değerine yakın görülmüştür.

"Dengeli bir entegre raporda bilgilerin seçiminde veya sunulmasında hiçbir şekilde önyargıya başvurulmaz. Rapordaki bilgiler olumlu ya da olumsuz algılanma olasılı̆̆ını değiştirecek şekilde bir yöne ĕgilimli, ăgırlıklı, vurgulu ya da vurgusuz, birleşik, kaymış veya başka şekilde maniple edilmiş olamaz" (IIRC, 2013: 21). Denge başlı̆̆ 1 altında yer alan bu ifadedeki bilgilerin seçiminde veya sunulmasında hiçbir şekilde önyargıya başvurulmaması kısmı iyimserlik değerine yakın görülmüștür.

"Denge sağlamada kullanılan önemli yöntemler şunlardir: Entegre rapora dayanarak yapılan değerlendirmeleri usulsüzce veya uygun olmayan şekilde etkileme ihtimali olmayan sunum formatlarının seçilmesi. Sermaye öğelerindeki artışve azalmalara, kuruluşun güçlü ve zaylf yönlerine, olumlu ve olumsuz performansa vb. eşit ağırlı verilmesi. Daha önce bildirilen hedeflere, tahminlere, öngörülere ve beklentilere göre raporlama yapılması" (IIRC, 2013: 22). Denge başlığı altında yer alan bu ifadedeki, sermaye öğelerindeki artış ve azalmalara, kuruluşun güçlü ve zayıf yönlerine, olumlu ve olumsuz performansa vb. eşit ağırlık verilmesi kısmı iyimserlik değerine yakın görülmüștür.

"Bir entegre raporda yer verilen bilgiler doğasl gereği iş yönetiminin temelinde yer alır. Buna göre, bir konu işi yönetmek açısından önemliyse konuyu uygun şekilde ele almak ve yönetmek için kritik bilgilerin edinilememesi bakımından maliyet bir faktör olarak düşünülmemelidir" (IIRC, 2013: 22). Maliyet/fayda başlığı altında yer alan maliyetin bir faktör olarak düşünülmemesi bölümü iyimserlik değerine yakın görülmüştür.

"Geleceğe yönelik bilgiler doğası gereği geçmişe dönük bilgilerden daha belirsizdir. Ancak belirsizlik, bu bilgileri hariç tutma açısından kendi içinde bir neden teşkil etmez" (IIRC, 2013: 22). Geleceğe yönelik bilgiler başlığı altında yer alan bu ifadedeki geleceğe yönelik bilgilerin hariç tutulmaması kısmı iyimserlik değerine yakın görülmüştür.

"Kuruluşun açıkladiğ beklentilerin, isteklerin ve niyetlerin gerçeklere dayanmasını săglamaya dikkat edilmelidir. Bunların, kuruluşun kendisine sunulan firsatlart (ilgili sermaye öğelerinin bulunabilirliği, kalitesi ve satın alınabilirliği dahil) kullanma kabiliyetiyle orantılı olması ve kuruluşun rekabet ortamı, pazardaki konumu ve karşılaştığı riskleri gerçekçi bir şekilde öngörmesi gerekir" (IIRC, 2013: 28). Genel görünüş başlığı altında yer alan bu ifadedeki kuruluşun beklentilerinin açıklanması kısmı iyimserlik değerine yakın görülmüștür.

"Gelecekteki finansal performans üzerindekiler dahil olmak üzere potansiyel etkiler genellikle aşağıdaki konular hakkında açıklamalar içerir: Dış çevre, riskler ve firsatlar ve bunların stratejik amaçlara ulaşmayı nasıl etkileyebileceğine 
ilişkin bir analiz. Kuruluşun kullandiğı veya etkilediği sermaye öğelerinin bulunabilirliği, kalitesi ve satın alınabilirliği (örneğin kalifiye işgücünün veya doğal kaynakların sürekli bulunabilir olması) ile temel ilişkilerin nasıl yönetildiği ve bunların, kuruluşun zaman içinde değer yaratma kabiliyeti açısından neden önemli olduğu" (IIRC, 2013: 29). Genel görünüş başlığı altında yer alan bu ifadedeki potansiyel etkilere dair açıklamalar kısmı iyimserlik değerine yakın görülmüştür.

\subsection{Uluslararasi Entegre Raporlama}

\section{Çerçevesinde Gizlilik Yerine Şeffaflık}

Uluslararası Entegre Raporlama Çerçevesine ait ifadeleri ve Gray'in muhasebe kültürü değerleri göz önün alındığında aşağıdaki önermeleri sunmak mümkün olacaktır.

Önerme 4.a: Uluslararası Entegre Raporlama Çerçevesi şeffaflık muhasebe kültür değerine daha yatkındır.

Önerme 4.b: Uluslararası Entegre Raporlama Çerçevesi gizlilik muhasebe kültür değerine daha yatkındır.

Gizlilik/Şeffaflık ile Uluslararası Entegre Raporlama Çerçevesi uyum düzeyi bu şekilde önerilmiştir. Yapılan inceleme sonucunda Uluslararası Entegre Raporlama Çerçevesinin şeffaflık ile on dokuz maddesi, gizlilik ile üç maddesi yakın görülmüştür. Uluslararası Entegre Raporlama Çerçevesinin Gray'in muhasebe değerlerinden şeffaflık ile daha fazla benzer yanları bulunmaktadır. Önermeleri güçlendirmek adına aşağıdaki incelemeler yapılmış ve bu benzerliklere ayrıntılı olarak yer verilmiştir.

\subsubsection{Uluslararast Entegre Raporlama Çerçevesinde Gizlilik Değeri \\ Gray'in gizlilik-şeffaflık muhasebe} değerlerine göre incelendiğ́ zaman Uluslararası Entegre Raporlama Çerçevesinin gizlilikten yana bir eğilim içinde olmadığ Uluslararası Entegre Raporlama Çerçevesinin gizlilik ile üç maddesi yakın görülmüştür. Gizlilik değerine yakın görülen az sayıdaki Uluslararası Entegre Raporlama Çerçevesi maddelerine ve bu maddelerin yakın görülme nedenlerine aşağıda ayrıntılı olarak yer verilmiştir.

"Bir entegre raporu hazırlama ve sunma amaclyla önemlilik belirleme sürecinde şunlar yapılır: Maddi konular hakkında açılanacak bilgilerin belirlenmesi" (IIRC, 2013: 18). Öncelik belirleme süreci başlığı altında yer alan bu ifadedeki maddi bilgilerin hepsinin değil belirli bir kısmının entegre raporda açıklanması kısmı gizlilik değerine yakın görülmüştür.

"Bir kuruluş, rekabet avantajı ile ilgili maddi konular (örneğin kritik stratejiler) hakkındaki bilgileri rapora dahil etme sürecinde konunun özünü, rekabette önemli avantaj kaybına neden olabilecek spesifik bilgileri açı̆̆a çıkarmadan nasıl açıklayacă̆ını göz önünde bulundurur. Kuruluş buna göre bir entegre raporda yer alan bilgilerden bir rakibinin ne tür bir kazanım să̆layacağını göz önünde bulundurur ve bunu, entegre raporun paragraf $1.7^{\prime}$ de açıklanan asıl amacını karşılaması ihtiyacina göre dengeler" (IIRC, 2013: 22). Rekabet avantajı başlığı altında yer alan bu ifadede özellikli bilgilerin açıklanması ve rakibin sağlayacağı kazanımlar kısımları gizlilik değerine yakın görülmüştür.

"Bir entegre raporda tüm girdilerin kapsaml bir listesi verilmez. Bunun yerine, türetildikleri sermaye öğelerinin kuruluşa ait olup olmadiğına baklmaksızın kisa, orta ve uzun vadede değer yaratma kabiliyeti üzerinde maddi öneme sahip olanlara odaklanır. Ayrica, girdilerin seçimini etkileyen önemli takas unsurlarının özellikleri ve büyüklüğü hakkında bir tartışma da içerebilir" (IIRC, 2013: 26). Girdiler başlığ 1 altında yer alan bu ifadedeki maddi öneme sahip olan girdilere odaklanma kısmı gizlilik değerine yakın görülmüştür.

\subsubsection{Uluslararast Entegre Raporlama Çerçevesinde Şeffaflık Değeri}

Gray'in gizlilik-şeffaflı muhasebe değerlerine göre incelendiği zaman Uluslararası Entegre Raporlama Çerçevesinin şeffaflıktan yana bir eğilim içinde olduğu yorumu yapılabilmektedir. Uluslararası Entegre Raporlama Çerçevesinin şeffaflık ile on dokuz maddesi yakın görülmüştür. Şeffaflık değerine yakın görülen Uluslararası Entegre Raporlama Çerçevesi maddelerine ve bu maddelerin yakın görülme nedenlerine aşağıda ayrıntılı olarak yer verilmiştir.

"Bir kuruluşun kendisi için değer yaratabilme kabiliyeti, finansal sermaye sağlayan taraflara finansal geri dönüs să̆lar. Bu, kuruluşun çok çeşitli faaliyetler, etkileşimler ve ilişkiler yoluyla paydaşları ve geniş anlamda toplum için yarattlğ $l$ değerle ilişkilidir. Bunlar kuruluşun kendisi için değer yaratma kabiliyeti açisından önemliyse entegre rapora dahil edilmeleri gerekir" (IIRC, 2013: 4). Temel kavramlar başlığı altında yer alan bu ifadedeki, kuruluşun geniş anlamda toplum için yarattığ değerlerin entegre rapora dahil edilmesi kısmı şeffaflık değerine yakın görülmüştür.

"Raporun ayrica, bir kuruluşun kisa, orta ve uzun vadede değer yaratmak amacıyla dış çevresiyle ve sermaye ögeleriyle nasıl etkileşim kurduğunu da açıklaması gerekir" (IIRC, 2013: 4). Temel kavramlar başlı̆gı altında yer alan bu ifadedeki, kurulan etkileşimin açıklanma gereksinimi şeffaflık değerine yakın görülmüştür.

"Güvenilirlik ve eksiksizlik: Bir entegre rapor olumlu ya da olumsuz tüm maddi hususları dengeli ve maddi hata içermeyecek bir şekilde içermelidir" (IIRC, 2013: 5). Kılavuz ilkeler başlığı altında yer alan bu ifadedeki olumlu ya da olumsuz tüm maddi 
unsurların entegre raporda yer alması kısmı şeffaflık değerine yakın görülmüştür.

"Bir entegre raporun asil amact finansal sermaye sağlayan taraflara bir kuruluşun zaman içinde nasıl dĕger yaratacă̆ını açıklamaktır. Dolayısiyla hem finansal hem de diğer konularda ilgili bilgiler içerir" (IIRC, 2013: 7). Entegre raporun amacı ve kullanıcıları başlığı altında yer alan bu ifadedeki kuruluş için yaratılacak değerin entegre raporda açıklanması kısmı şeffaflık değerine yakın görülmüştür.

"Ilgili bilgilerin veya spesifik yasal engellerin bulunmamast halinde bir entegre rapor: Atlanan bilgilerin niteliğini göstermelidir. Bu bilgilerin neden atlandiğını açıklamalıdır" (IIRC, 2013: 8). Çerçevenin uygulanışı başlığı altında yer alan bu ifadedeki atlanan bilgilerin açıklanması isteği şeffaflık değerine yakın görülmüştür.

"Bir stratejik odak ve geleceğe yönelim belirlemek için önemli sermaye ögelerinin sürdürülen bulunabilirliğinin, kalitesinin ve satın alınabilirliğinin kuruluşun gelecekte stratejik hedeflerine ulaşma ve değer yaratma kabiliyetine nasıl katkıda bulunacağının net bir şekilde ortaya konmasl gerekir" (IIRC, 2013: 16). Stratejik odak ve geleceğe yönelim başlığı altında yer alan bu ifadedeki gelecekte hedeflere ulaşma ve değer yaratma yeteneğine katkıda bulunma şeklinin net bir şekilde ortaya konması vurgusu şeffaflık değerine yakın görülmüştür.

"Bir entegre rapor kuruluşun temel paydaşlarıyla kurduğu ilişkilerin doğası ve kalitesi hakkında bilgi sağlamalı ve kuruluşun paydaşların meşru ihtiyaç ve isteklerini ne ölçüde anladığını, hesaba kattığını ve karşıladığını göstermelidir" (IIRC, 2013: 17). Paydaşlarla ilişkiler başlığı altında yer alan bu ifadedeki entegre raporun paydaşlarıyla kurduğu ilişkiler hakkında bilgi sağlama kısmı şeffaflık değerine yakın görülmüștür.

"Bir entegre rapor, başlica paydaşlarin meşru ihtiyaç ve isteklerinin nasıl anlaşıldı̆̆ını, dikkate alındığını ve alınan kararlar, yapılan işler, performans ve sürekli iletişim yoluyla nasil karşılandı̆̆ını açıklayarak, güven ve esneklik oluşturmada çok önemli rol oynayan şeffaflığl ve hesap verebilirliği güçlendirir" (IIRC, 2013: 18). Paydaşlarla ilişkiler başlığı altında yer alan bu ifadedeki entegre raporun şeffaflığ verilebilirliği güçlendirmesi kısmı şeffaflık değerine yakın görülmüştür.

"Tüm ilgili konular önemli olarak kabul edilmez. Bir konunun entegre rapora dahil edilmesi için değer yaratma üzerindeki bilinen veya potansiyel etkisi bakımından yeterince önemli olmast gerekir. Bunun için konunun etkisinin ne derece büyük olduğu ve gerçekleşip gerçekleşmeyeceği belirsizse meydana gelme olasilığl değerlendirilmelidir" (IIRC, 2013: 19). Önemin değerlendirilmesi başlığ bu ifadedeki gerçekleşmesi belirsiz olan konuların bile meydana gelme olasılığının değerlendirilmesi vurgusu şeffaflık değerine yakın görülmüştür.

"Kuruluş, entegre raporunda kisa ve öz olma ile özellikle eksiksizlik ve karşılaştırılabilirlik gibi diğer Kllavuz İlkeler arasında denge kurmaya çalışır” (IIRC, 2013: 21). Kısa ve öz olma başlığ1 altında yer alan bu ifadedeki, kısa ve öz olma ile eksiksizlik ve karşılaştırılabilirlik arasında denge kurmaya çalışması kısmı şeffaflık değerine yakın görülmüştür.

"Bir entegre rapor hazırlanırken bir denetim düzeni oluşturulmast üst düzey yönetime ve kurumsal yönetim sorumlularina raporu incelemede ve bilgilerin rapora dahil edilmeye yeterli ilgiye sahip olup olmadığını belirlemede yardımcı olur. Bazı durumlarda (örneğin geleceğe yönelik bilgiler açısından) bir entegre raporun güvenilirliği sağlamak için kullanılan mekanizmaları açıklaması gerekebilir" (IIRC, 2013: 21). Güvenilirlik başlığ1 altında yer alan bu ifadedeki güvenilirliği sağlamak için kullanılan mekanizmaların açıklanması kısmı şeffaflık değerine yakın görülmüştür.

"Maddi hata içermeme demek bilginin her açıdan tamamen kesin olması demek değildir. Şu anlama gelir: Tahmin içeren bilgilerin net bir şekilde bildirilmesi ve tahmin süreçlerinin özellikleri ve sınırlamalarının açıklanması sağlanmıştır" (IIRC, 2013: 22). Maddi hata içermeme başlığ alan bu ifadedeki tahmin içeren bilgilerin de bildirilmesi vurgusu şeffaflık değerine yakın görülmüştür.

"Eksiksiz bir raporda hem pozitif hem negatif tüm gerekli bilgiler yer alır" (IIRC, 2013: 22). Eksiksizlik başlığı altında yer alan bu ifadedeki olumlu ve olumsuz bilgilerin entegre raporda yer alması kısmı şeffaflık değerine yakın görülmüştür.

"Önemli bir değişiklik gerçekleş̧tiğinde, kuruluş değişikliğin nedenini ve etkisini açılar (ve uygulanabilir ve maddi açıdan önemliyse niceliğini bildirir)" (IIRC, 2013: 23). Tutarlılık başlığı altında yer alan bu ifadedeki değişikliği açıklama vurgusu şeffaflık değerine yakın görülmüştür.

"İs modeli açıklamasının etkinliğini ve okunabilirliğini güçlendiren özellikler şunlardır: $\dot{I S S ̧}_{\text {ș }}$ modelinin temel öğeleri hakkında net bir açıklama. Temel öğeleri vurgulayan basit bir şema ve bunu desteklemek üzere bu öğelerin kuruluş açısından ilgisi hakkında net bir açıklama. Kuruluşun içinde bulunduğu koşullara uygun, mantıklı bir metin akışı. Başlıca paydaşlar ile dış çevreyi etkileyen diğer bağımlilıklar (örneğin ham madde) ve önemli faktörler hakkında açıklama" (IIRC, 2013: 25). İş modeli başlığı altında yer alan bu ifadedeki iş modeli hakkında net açıklama kısmı ve önemli faktörler hakkında açıklama kısmı şeffaflık değerine yakın görülmüştür. 
"Bir entegre raporda temel iş faaliyetleri açıklanır. Aşağıdakileri içerebilir: Kuruluş pazarda kendisini nasıl farklılaştırlyor (örneğin ürün farklılaşması, pazar segmentasyonu, teslimat kanalları ve pazarlama). Işs modeli ilk satış noktasından sonra gelir yaratmaya ne ölçüde dayalı (örneğin genişletilmiş garanti anlaşmalart veya ăg kullanım ücretleri). Kuruluş, yenilikçilik ihtiyacına nasıl yaklaşıyor. İs modeli değişime uyum sağlamak için nasıl tasarlanmıştır" (IIRC, 2013: 26). İş faaliyetleri başlığ 1 altında yer alan bu ifadedeki temel iş faaliyetleri hakkında açıklamalar kısmı şeffaflık değerine yakın görülmüştür.

"Bir entegre raporda aşağıdakiler gibi temel sonuçlar açılanır: Olumlu sonuçlar (yani sermaye ögelerinde net artışla sonuçlanan ve dolayısıyla değer yaratanlar) ve olumsuz sonuçlar (yani sermaye ögelerinde net azalmayla sonuçlanan ve dolayısiyla değeri azaltanlar)" (IIRC, 2013: 26). Sonuçlar başlı̆̆ 1 altında yer alan bu ifadedeki hem olumlu hem de olumsuz sonuçların entegre raporda açıklanması vurgusu şeffaflık değerine yakın görülmüştür.

"Bir entegre raporda normalde zaman içinde beklenen değişiklikler vurgulanır ve aşağıdaki hususlar hakkinda yapılan güvenilir ve şeffaf analizlerle elde edilen bilgiler sağlanır: Kuruluşun kısa, orta ve uzun vadede dış çevresinde karşılaşması muhtemel durumlar hakkindaki beklentileri. Bunun kuruluşu nasıl etkileyeceği. Kuruluşun halihazırda karşısına çıkması muhtemel kritik zorluklara ve belirsizliklere yanıt vermek için nasıl teşkilatlandiğ (IIRC, 2013: 28). Genel görünüş başlığı altında yer alan bu ifadedeki güvenilir ve şeffaf analizlerle bilgilerin elde edilmesi kısmı şeffaflık değerine yakın görülmüştür.

"KPI'lar gibi nicel göstergeler karşılaştırılabilirliği güçlendirmeye yardımcı olur ve özellikle hedeflere göre bulunulan konumu açılamaya ve rapor etmeye yardımcı olur" (IIRC, 2013: 31). Nicel göstergelerin özellikleri başlı̆̆1 altında yer alan bu ifadedeki nicel göstergelerin bulunulan konumu açıklamaya ve rapor etmeye yardımcı olması kısmı şeffaflık değerine yakın görülmüştür.

\section{SONUÇ}

Uluslararası Entegre Raporlama Çerçevesi ve Gray'in muhasebe değerleri bir arada ele alındığında benzer yanları göze çarpmaktadır. Bu benzerliklerden yola çıkarak Uluslararası Entegre Raporlama Çerçevesinin muhasebe kültürü değerlerine eğilimi üzerine önermelerde bulunulmuştur.
Statükoculuk/Profesyonellik ile Uluslararas1 Entegre Raporlama Çerçevesi uyum düzeyi hakkında önermelerde bulunulmuştur. Önermeleri güçlendirmek adına yapılan incelemeler sonucunda Uluslararası Entegre Raporlama Çerçevesinin Gray'in muhasebe değerlerinden profesyonellikle daha fazla benzer yanları bulunduğu yorumu yapılabilmektedir.

Tekdüzelik/Esneklik ile Uluslararası Entegre Raporlama Çerçevesi uyum düzeyi hakkında önermelerde bulunulmuştur. Önermeleri güçlendirmek adına yapılan incelemeler yapılmıştır. Uluslararası Entegre Raporlama Çerçevesinin Gray'in muhasebe değerlerinden hem tekdüzelik hem de esneklikle benzer yanları bulunmaktadır. Fakat az farkla da olsa esneklikten yana bir eğilim içinde olduğu söylenebilir.

Tutuculuk/Iyimserlik ile Uluslararası Entegre Raporlama Çerçevesi uyum düzeyi hakkında önermelerde bulunulmuştur. Önermeleri güçlendirmek adına yapılan incelemeler sonucunda Uluslararas1 Entegre Raporlama Çerçevesinin Gray'in muhasebe değerlerinden tutuculuk ile daha fazla benzer yanları bulunduğu yorumu yapılabilmektedir.

Gizlilik/Şeffaflık ile Uluslararası Entegre Raporlama Çerçevesi uyum düzeyi düzeyi hakkında önermelerde bulunulmuştur. Önermeleri güçlendirmek adına yapılan incelemeler sonucunda Uluslararası Entegre Raporlama Çerçevesinin Gray'in muhasebe değerlerinden şeffaflık ile daha fazla benzer yanları bulunduğu yorumu yapılabilmektedir.

Sonuç olarak, Uluslararası Entegre Raporlama Çerçevesi Gray'in muhasebe kültürü değerlerine göre incelendiği zaman profesyonellikten, esneklikten, tutuculuktan ve şeffaflıktan yana bir eğilim içinde olduğu yorumu yapilabilmektedir. Türkiyede'ki muhasebe kültürü ile Uluslararası Entegre Raporlama Çerçevesi karşılaştırıldığında ikisinin de profesyonellikten, tutuculuktan ve şeffaflıktan yana bir eğilim içinde olduğu yorumu yapılabilmektedir. Farklı olarak Türkiye'deki muhasebe kültürü tekdüzelikten yanayken Uluslararası Entegre Raporlama Çerçevesi esneklikten yanadır. Uluslararası Entegre Raporlama Çerçevesi, dünya çapında bir koalisyon olan Uluslararas1 Entegre Raporlama Konseyi tarafindan yayınlanmıştır. Düzenleyici kurumların, yatırımcıların, işletmelerin, muhasebe uzmanlarının, standart belirleme otoritelerinin ve Sivil Toplum Kuruluşlarının katkılarından yola çıkılarak bir konsey tarafından yayımlanan bu çerçevede esnekliğin ön planda olmasının nedeni, bu ortaklaşa çalışma olarak gösterilebilir. 


\section{KAYNAKÇA}

Ağdeniz, Ş. (2018). Entegre Raporlamada İç Denetimin Rolü. Mali Çözüm Dergisi, 121-138.

Aras, G., ve Uğur Sarığlu, G. (2015). Kurumsal Raporlamada Yeni Dönem: Entegre Raporlama. İstanbul: Tüsiad.

Ataman Gökçen, B., ve Eldemir, E. (2019). Entegre Raporlama ve Türk İşletmelerinde Uygulanmasına İlişkin Bir Araştırma. Finans Ekonomi ve Sosyal Araştırmalar Dergisi, 357-378.

Bekci, İ., ve Bitlisli, F. (2012). Muhasebe-Kültür Değerlerinin Analizi: Muhasebe Meslek Mensupları Üzerine Bir Araştırma. C.Ü. İktisadi ve İdari Bilimler Dergisi, 61-76.

Borsa İstanbul. (2014, Ekim). Şirketler için Sürdürülebilirlik Rehberi. Borsa İstanbul Web Sitesi:

http://www.borsaistanbul.com/data/kilavuzlar/surd urulebilirlik-rehberi.pdf adresinden alındı

Bratu, A. (2017). Empricial Study Regarding the Integrated Reporting Practices in Europe. Audit Financiar, 613-627.

Choi, J.-S. (2002). Financial Crisis and Accounting Reform : A Cultural Perspective. 4th APIRA Conference (s. 71-93). Adelaide: Journal of Accounting and Finance.

Dereköy, F. (2018). Entegre Raporlama Uygulamalarının Uluslararas1 Entegre Raporlama Çerçevesi Bağlamında Değerlendirilmesi. Yönetim Bilimleri Dergisi, 508-608.

Duman, S. (2007, Ocak). İSO 500 Büyük Sanayi Kuruluşunun Muhasebe Kültürünün Araştırılması. Sakarya: Sakarya Üniversitesi Sosyal Bilimler Enstitüsü.

Durmuş, A. F., ve Güneş, R. (2017). Türkiye'deki Yeminli Mali Müşavirlerin Kültür Bazlı Muhasebe Değerlerinin Analizi. Muhasebe ve Finansman Dergisi, 81-98.

Ercan, C., ve Kestane, A. (2017). Entegre Raporlama ve Türkiye'deki Uygulama Örnekleri Üzerine Bir Araştırma. Kırklareli Üniversitesi İktisadi ve İdari Bilimler Fakültesi Dergisi, 73-86.

Gray, S. J. (1988). Towards a Theory of Cultural Influence on the Development of Accounting. Abacus, 1-15.

IIRC. (2013). Uluslararası <ER $>$ Çerçevesi. International Integrated Reporting Council (IIRC).

Işgüden Kılıç, B. (2018). Entegre Raporlama ve Türkiye'deki Gelişmeler: Entegre Rapor
Hazırlayan İşletmeler ve Bist Kurumsal Sürdürülebilirlik Endeksinde Yer Alan İşletmeler Açısından Bir İnceleme. Muhasebe Bilim Dünyası Dergisi, 28-64.

Karabınar, S. (2005). Kültür-Muhasebe Etkileşimi Açısından Muhasebe İklimi: Muhasebeye Kültürel Bakışlar. Seçkin Yayıncılık.

Karabınar, S., ve Güvenç, N. (2006). İçel İlinde Faaliyet Gösteren Bağımsı Muhasebe Meslek Mensuplarının Kültür Bazlı Muhasebe Değerleri. Muhasebe ve Finansman Dergisi, 210-217.

Kıymık, H. (2015). Örgütsel Kültür ve Örgütsel Muhasebe Kültürü ile Hileli Finansal Raporlama Arasındaki İlişki: BİST Hizmet Endeksinde Araştırma. Isparta: Süleyman Demirel Üniversitesi Sosyal Bilimler Enstitüsü.

Koleśnik, K. (2013). The Role of Culture in Accounting in The Light of Hofstede's, Gray's and Schwartz's Cultural Dimensions Theories - A Literature Review. Financial Internet Quarterly 'e-Finanse', s. 33-41.

Meyrick, J. (2016). Telling the Story of Culture's Value: Ideal-Type Analysis and Integrated Reporting. Journal of Arts Management, Law \& Society, s. 141-152.

Özdaşl1, E. (2017). Muhasebe Kültürü Değerlerinin Muhasebe Meslek Mensuplarının İçsel ve Dışsal Motivasyonları Üzerine Etkisi: Bir Araştırma. Burdur: Mehmet Akif Ersoy Üniversitesi Sosyal Bilimler Enstitüsü.

Raimo, N., Zito, M., ve Caragnano, A. (2019). Does National Culture Affect Integrated Reporting Quality? A Focus on GLOBE Dimensions. Zaječar, Serbia: ZBW - Leibniz Information Centre for Economics.

Saban, M., Vargün, H., ve Gürkan, S. (2017). Yatırımcılara Bilgi Sağlama Aracı olarak Entegre Raporlama. Muhasebe Bilim Dünyası Dergisi, 915-936.

Serafeim, G. (2016, Nisan). Integrated Reporting. Institute of Management Accountants: http://www.imanet.org///media/0830fcd907cd41a7bd760b8900fe7b94.ash $\mathrm{x} ? \mathrm{as}=1 \& \mathrm{mh}=200 \& \mathrm{mw}=200 \&$ hash $=$ AB7FF33967 6C03AA8B034BC0B42BD1381BB84A08 adresinden alındı

Tecimer, Y. (2010, Aralık). Halka Açık Şirketlerde Muhasebe Kültür Değerlerine Yönelik Bir Araştırma. Sakarya: Sakarya Üniversitesi Sosyal Bilimler Enstitüsü.

Vitolla, F., Raimo, N., Rubino, M., ve Garzoni, A. (2019, Aralık). The Impact of National Culture on Integrated Reporting Quality. A Stakeholder 
Theory Approach. Business Strategy and The Environment, s. 1-14.

Yeloğlu, H. O. (2011). Türk Toplumsal Kültürünün Örgüt Yapılarına Olan Etkilerinin Belirlenmesine Yönelik Bir Çalışma. ODÜ Sosyal Bilimler Enstitüsü Sosyal Bilimler Araştırmaları Dergisi, 153-170.

Yüksel, F. (2018). Entegre Raporlama ve Finansal Performans İlişkisi: Türkiye ve Güney Afrika Katılım Bankaları Üzerinde Bir Araştırma. Kırklareli Üniversitesi İktisadi ve İdari Bilimler Fakültesi Dergisi, 1-17.

Yüksel, F., ve Aracı, H. (2017). Hizmet İşletmelerine Ait Raporların Entegre Raporlama İlkeleri Açısından İncelenmesi. Uluslararası İktisadi ve İdari İncelemeler Dergisi, 729-748. 